\title{
Quintais urbanos de Mirassol D'Oeste-MT, Brasil: uma abordagem etnobotânica
}

\author{
Maria Antonia CARNIELLO' ${ }^{1}$, Roberta dos Santos SILVA², Maria Ap. Berbem da CRUZ³ e \\ Germano GUARIM NETO ${ }^{4}$. \\ RESUMO \\ Quintais são espaços de fácil acesso e cômodos para os moradores cultivarem uma diversidade de espécies que desempenham \\ funções de estética, lazer, alimentação e medicinal, dentre outras. O objetivo deste trabalho foi o de descrever a composição \\ florística e a respectiva utilização em quintais urbanos de Mirassol D’Oeste, MT, (15 45’30”S e 058¹6’36”W), com a coleta \\ de dados envolvendo: entrevistas estruturadas e semi-estruturadas aplicadas a 29 moradores; coleta simultânea do material \\ botânico das espécies indicadas, incorporação destas no Laboratório de Botânica da UNEMAT, Cáceres e análise da freqüência \\ absoluta e relativa das espécies mais citadas e encontradas nos quintais. Foram registradas 397 denominaçóes locais de plantas \\ (etnoespécies), 275 taxa reunidos em 79 famílias destacando-se com maior número de espécies: Solanaceae (23), Asteraceae \\ (17), Lamiaceae (14), Rosaceae (12) e Verbenaceae (9). Os atributos alimentar e ornamental representam, individualmente, \\ $35 \%$ das espécies e o medicinal, 29\%. Algumas plantas detêm até quatro potencialidades. Do universo vegetal conhecido \\ e utilizado localmente as espécies nativas correspondem a $8 \%$, resultado considerado baixo comparando-se aos obtidos em \\ populaçóes mato-grossenses radicadas no Cerrado e Pantanal. Essa população manifesta por meio de suas práticas uma tradição \\ agrícola em interface às características de uma sociedade urbano - industrial coabitando em espaços comuns, o quintal.
}

PALAVRAS-CHAVE: Composição florística, etnobotânica, quintais urbanos.

\section{Urban homegardens of Mirassol D'Oeste-MT, Brazil: an ethnobotany stady}

\begin{abstract}
A home garden is a small track of ground next to or surrounding a house where its residents can cultivate a diversity of plants, whose function is aesthetic, leisure, food, medicinal among others. The aim of this work was to study the floristic composition of urban homegardens in the city of Mirassol D'Oeste, state of Mato Grosso, coordinate 1545'30"S and 58¹6'36”W. For colleting data we interviewed 29 residents using structured and semi-structured interviews; and, simultaneously collected botanical species which we analysed at the Mato Grosso State University Botanical Laboratory, in Cáceres. We made statistical analyses using absolute frequency and relative frequency to quantify and specify the botanical species found in the gardens. We registered a total of 397 ethnobotanical species and grouped 275 taxa in 79 botanical families. The highest numbers among them were 23 species of Solanaceae, 17 Asteraceae, 14 Lamiaceae, 12 Rosaceae and 9 species of Verbenaceae. Food and ornamental attributes represented $35 \%$ of the species and medicinal $29 \%$. Some species had up to four potentialities. From the known plant universe used locally, native species corresponded to $8 \%$. This percentage was considered low when compared to that of the population living in the Pantanal and cerrado areas. This population demonstrated an interface between agricultural tradition and the characteristics of urban-industrial society living in common spaces: the homegardens.
\end{abstract}

KEYWORDS: Floristic composition, ethnobotany, urban homegardens.

1.Universidade do Estado de Mato Grosso - UNEMAT/Cáceres. carnielo@terra.com.br. Autora para correspondência (Rua da Maravilha nº. 124. Edifício Rancho Verde Apto52, Cavalhada - CEP:78.200-000, Cáceres, MT. 2. Universidade Federal de Viçosa - Doutoranda em Biologia Vegetal pelo Departamento de Botânica.

3. Bióloga do Magistério Público de Mato Grosso.

4. IB/UFMT - Departamento de Botânica e Ecologia, Cuiabá, MT. 


\section{INTRODUÇÃO}

Com característica interdisciplinar a etnobotânica abrange estudos que tratam das relaçóes estabelecidas por comunidades humanas com o componente vegetal. Para Alcorn (1997), a etnobotânica é uma ciência que, atualmente, prima pelo registro sobre as relações estabelecidas entre comunidades humanas e plantas, de forma contextualizada. Tais interrelaçôes são efetivadas no cotidiano de populaçốes com os seus respectivos locais de origem, assim como onde se estabelecem em virtude do processo migratório. São modeladas pela história da comunidade, pelo ambiente físico, social e ainda pelas qualidades inerentes às próprias plantas (Caballero, 1979; Prance, 2000).

Acerca dessas inter-relaçôes vêm sendo realizadas investigaçôes com povos de várias matrizes culturais e organizaçôes sociais, os quais estão estabelecidos em diferentes unidades de paisagem e regióes do planeta. O quintal é uma unidade de paisagem no qual são adotados manejos concebidos e executados de maneira harmoniosa envolvendo diferentes formas de vida (Kumar e Nair, 2004). Esses autores afirmam, ainda, que o elevado número de espécies encontrado nos quintais e as interaçóes estabelecidas com os respectivos idealizadores satisfazem necessidades econômica, social e cultural específicas do grupo envolvido. No âmbito mais amplo e de alcance para a coletividade essas interaçóes provêm à conservaçáo biológica e o seqüestro de carbono entre outros benefícios.

Estudos etnobotânicos recentes têm enfocado o quintal rural (Saraguossi et al., 1990; Noda e Noda, 2003) e o urbano (Martins, 1998), dentre outros, como uma importante unidade de paisagem reveladora da incorporação, uso e conservação de biodiversidade. Os quintais podem ser considerados relevantes depositários de germoplasma, além de outros aspectos como segurança alimentar, estético e cultural (Amorozo, 2002a). Para Freire et al. (2005), o quintal é um laboratório da vida no contexto da agricultura familiar, enquanto que para Oakley (2004), a conservação dos quintais é uma responsabilidade cultural.

No mosaico da arquitetura urbana no Brasil, o quintal é um elemento fortemente destacado em todos os períodos da história de formaçâo dos conglomerados urbanos. É um espaço marcado por uma intensa ligação com atividades próprias das sociedades agrícolas que ao se transferirem para o meio urbano passaram a reproduzir práticas do meio rural em dimensóes territoriais reduzidas. Segundo Silva (2004), em condomínios verticais a área de serviço constitui “... uma reminiscência do quintal...” Ele argumenta, ainda, que nos últimos dois séculos os quintais no meio urbano têm persistido nos projetos arquitetônicos com espaço ínfimo e as funçôes foram gradativamente descaracterizadas em relação à respectiva origem.
Os dois processos considerados de maior impacto na estabilidade de quintais em diversas partes do mundo são: o atual modelo de crescimento econômico que envolve as áreas rurais e urbanas e o crescimento da população (Soemarwoto e Conway, 1992). Ambos têm motivado a concentração de pessoas nos centros urbanos, em espaços planejados e prédefinidos horizontal e verticalmente. Ressalta-se que nas periferias dos centros urbanos, o planejamento é precário ou inexistente na maioria das cidades brasileiras.

Alguns estudos revelaram que nos centros urbanos, embora dispondo de diminutos espaços, povos dotados do hábito de cultivar plantas têm mantido os seus quintais, os quais têm se constituído em acervos de espécies raras e de remanescentes da composição florística local (Ferreira e Dias, 1993; Amorozo, 2002a; 2002b).

Trabalhos realizados em quintais, manejados por povos de diferentes culturas e localizados no território matogrossense, têm possibilitado o registro do arranjo desse espaço, envolvendo a estrutura de organização, a composição, o manejo e a funçáo das plantas (Ferreira e Dias, 1993; Brito e Coelho, 2000; Amorozo, 2002a; 2002b; Santos, 2004; Pasa et al., 2005). Esses trabalhos estão concentrados principalmente na Baixada Cuiabana e no norte do Estado, em áreas florestais.

Estudos etnobotânicos em Mato Grosso são necessários devido a três aspectos principais: a privilegiada extensão territorial com remanescentes da cobertura vegetal composta por Floresta, Cerrado (lato sensu), Pantanal e os ecótonos entre estes; a diversidade cultural composta por cerca de 40 povos indígenas (Brasil, 2001), populaçôes afro-descendentes e migrantes de origem européia entre outras; e o acelerado processo de mecanização/industrialização da agricultura e expansão da fronteira agropecuária a que estão submetidos, motivando o deslocamento da população para os centros urbanos.

Neste contexto, o objetivo deste trabalho é o de registrar a composição florística e as relaçóes estabelecidas pela população com as espécies vegetais presentes em quintais urbanos de Mirassol D’Oeste, no sudoeste de Mato Grosso, em área florestal.

\section{MATERIAL E MÉTODOS}

Área de estudo - Está situada na região da borda noroeste do Pantanal em torno das coordenadas 15045'30"S e $58^{\circ} 16^{\prime} 36^{\prime \prime W}$. O Município de Mirassol D’Oeste pertence à microrregião do Vale do Jauru e sua área encontra-se distribuída em três bacias sendo a do rio Jauru, do Córrego Padre Inácio e do rio Cabaçal, compreendendo respectivamente 36,38\%, $28,22 \%$ e $35,40 \%$ da extensão total do município. (Figura1). 


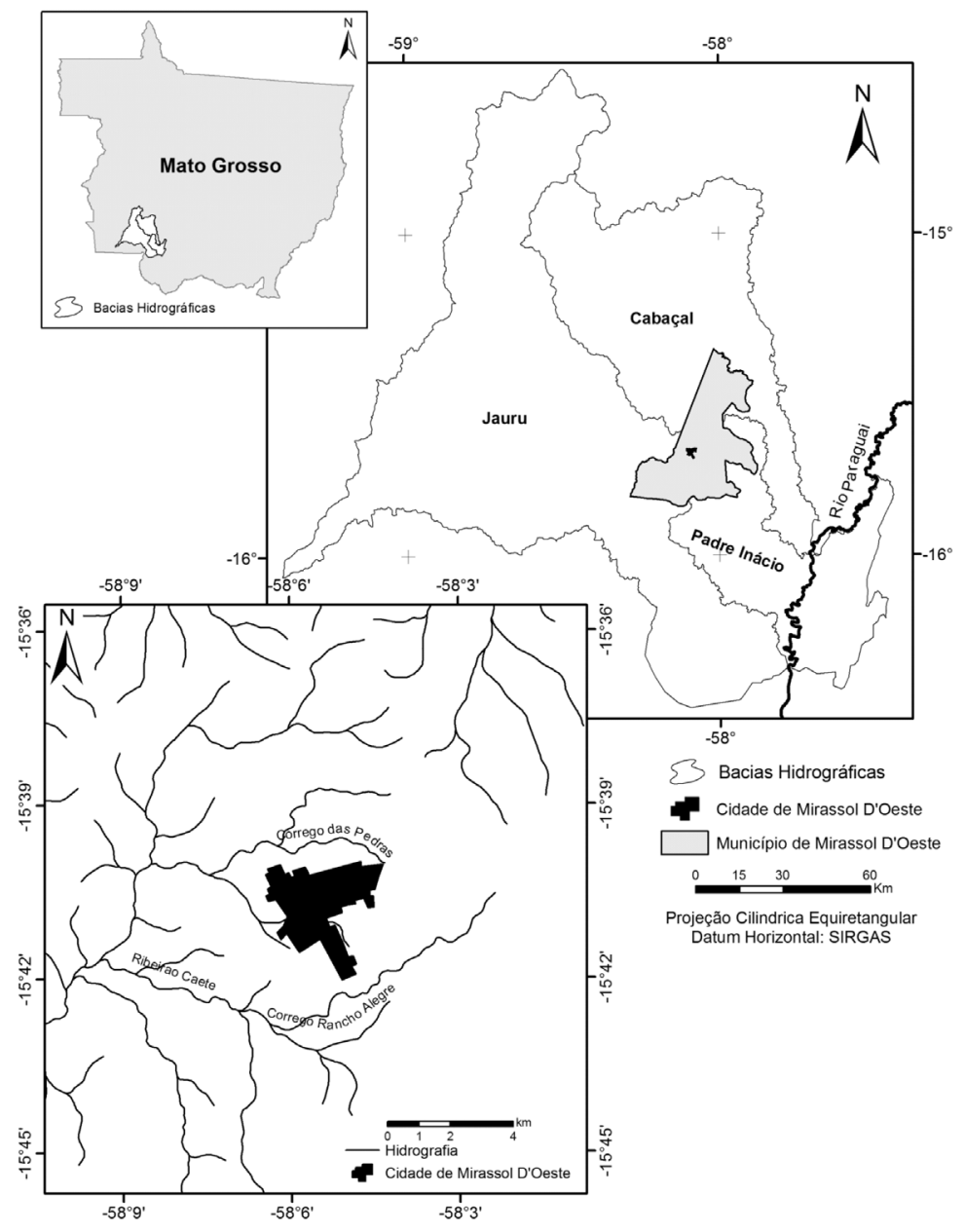

Figura 1 - Localização da área de estudo: Mirassol D’Oeste, MT. Mapa organizado por Carniello e Neves (2008), SERPEGEO/Laboratório de Geotecnologias/ UNEMAT.

O relevo é caracterizado como depressão do rio Paraguai, calha do Jauru, especificamente na porção que alcança os limites entre as bacias Platina e Amazônica.

A cobertura vegetal está caracterizada como uma importante área onde convergem características vegetacionais remanescentes de cerrado (sensu lato), também sob a influência das áreas úmidas do Pantanal, e ainda, com a presença de fragmentos de Floresta Amazônica com algumas áreas ecotonais sujeitas à grande pressão provocada pela ocupação e uso da terra. Cerca de $80 \%$ de toda a cobertura vegetal do município foi substituída por cultivos agrícolas diversificados, implantados nos últimos 30 anos. Dois fragmentos vegetacionais estấo localizados próximos ao meio urbano e cobrem as Serras Tamandaré e Sonho Azul-Cacho. Ambas distam entre um e cinco quilômetros do centro urbano e estão sob intensa pressão antrópica em face às pastagens e lavouras implantadas no entorno (Miranda e Amorim, 2001; SEPLAN/ MT (http://www.seplan.mt.gov.br) Acesso: 03/02/05.

A economia do município está baseada nas atividades de pecuária, agricultura, agroindústria e comércio. Conforme FIBGE (2000) e dados da Secretaria de Fazenda de Mirassol D'Oeste (2004, banco de cadastro urbano), na sede do município residem 16.938 habitantes correspondendo a 73 $\%$ da população total do município. O número de domicílios ocupados exclusivamente como residência é de 3.764.

Procedimentos de coleta e análise dos dados - As estratégias de coleta e tratamento dos dados adotados no presente estudo seguem os métodos propostos por Bernard (1988), Martin (1995), e também às orientaçôes teórico-práticas discutidas por Amorozo (1996), Ming (1996) e Albuquerque (2002). A coleta de dados teve a duração de 18 meses, entre anos de 2003 e 2004. 
Foram estabelecidas três fases de contato com a comunidade que compreendeu: 1) delimitaçáo da área de estudo envolvendo todos os bairros da sede do município, 2) observação exploratória para diagnóstico dos domicílios que apresentavam no mínimo 40 espécies vegetais manejadas e consideradas úteis pelo respectivo responsável. No final desta fase foi estabelecida uma amostra de $5 \%$ dos quintais abrangendo todos os bairros da cidade. A escolha foi fundamentada nas características anteriormente descritas. $\mathrm{Na}$ fase três foram realizadas entrevistas orientadas por um roteiro semi-estruturado (perguntas abertas e fechada) caracterizando o perfil do informante quanto aos aspectos culturais, socioeconômicos e forma de utilização do domicílio. Em seguida o domicílio foi caracterizado quanto a sua extensão, período de fundação, composição florística, manejo adotado no cultivo de plantas, formas de uso e processamento para obtensão dos produtos advindos dos recursos vegetais do quintal. As entrevistas foram realizadas com os responsáveis pelos domicílios, sendo 19 mulheres e 10 homens, cuja faixa etária compreende 28 a 78 anos.

$\mathrm{Na}$ coleta de dados foi adotada a observação participante de acordo com o que dispôem Lüdke e André (1986), Bernard (1988), Alexíades (1996) e Amorozo (1996). A última autora sintetiza as proposiçóes dos autores mencionados afirmando que "a observação participante é um método tradicionalmente usado em antropologia, que consiste na apreensão, por meio de uma interação cotidiana entre o pesquisador e os membros da comunidade estudada, da forma como opera a cultura em questão e como os atores sociais vêem o seu mundo. Ela poderá proporcionar o cenário sobre o qual se dá o uso de plantas." As técnicas de observação participante perpassaram por todas as atividades desenvolvidas durante o período de coleta e análise dos dados nos quintais amostrados. Também foram incluídos dados coletados esporadicamente durante o ano de 2004. Simultaneamente, foi preparada uma coleçấo testemunha do material botânico indicado pela populaçấo. As coletas e o tratamento desse material foram realizados em conformidade com FIBGE (1992). O material herborizado foi identificado nas seguintes instituiçôes pelos respectivos especialistas: EMBRAPA/MS: Lima, L., Pott, A. e Pott, V. J.; ESALQ: Forster, W.; Instituto de Botânica de São Paulo: Duarte, M. C., Mamede, M. C. H. e Sugeyama, M.; UFMS: Damasceno Junior, G.; UFMT: Guarim Neto, G.; UFSC: Zanin, A.; UFV: Santos-Silva, R. e Ferreira, S. da C.; UNEMAT: Andrade, A. L., Amorim, P. R. F. e Carniello, M. A.; UNESP: Assis, M. A., Braz, D. M., Cavalheiro, L., Dittrich, V. A. de O., Furlan, A., Rampim, V. T., Toroda, N., Udulutsch, R.G. e UNICAMP: Sumiko, L.. A base de dados adotada na elaboração da lista das plantas fanerogâmicas é a de Stevens (2004) - (APGII, Angiosperm Phylogeny Group) e Souza e Lorenzi (2005), exceto para a família Liliaceae mantida sensu Cronquist (1981). Para o grupo das Samambaias foi seguido o que dispóe Moran (1995). A coleção testemunha está depositada no Laboratório de Botânica da UNEMAT, em Cáceres-MT. As duplicatas foram doadas para os herbários das instituiçôes de vínculo dos especialistas colaboradores deste trabalho, acima destacados. Para a classificaçáo dos hábitos das plantas foi adotada a classificação de IBGE (1992), complementada por Ribeiro et al. (1999).

Foram realizadas análises de freqüência absoluta (Fa.) e freqüência relativa $(\mathrm{Fr}$.) de quintais com a presença das espécies mais importantes compreendendo as citadas pelos informantes e encontradas nos quintais estudados, onde: $\mathrm{Fa}=$ número de quintais de ocorrência da espécie considerada (qti), e $\operatorname{Fr}=[\mathrm{n}(\mathrm{qti}) / \Sigma \mathrm{qt}] \times 100$; sendo 29, o número total de quintais amostrados (qt).

Os depoimentos incluídos no texto estão identificados em conformidade com as recomendaçôes adotadas em trabalhos com comunidades humanas, compreendendo a idade e as iniciais do nome.

\section{RESULTADOS E DISCUSSÃO}

\section{PERFIL SOCIOECONÔMICO DOS INFORMANTES E CARACTERIZAÇÃO DOS DOMICÍLIOS}

A população entrevistada é imigrante e apresentou forte ligaçáo com a atividade agrícola. São procedentes de nove estados do Brasil sendo $76 \%$ oriundos da região sudeste. $\mathrm{O}$ itinerário de locais de procedência desta populaçáo revelou que $82,75 \%$ residiram no meio rural por um período correspondente à metade de suas vidas e 73\%, em alguma fase da vida dedicaram-se a alguma atividade agrícola. Atualmente são proprietários e residem no mesmo domicílio há aproximadamente dez anos. Do universo investigado $90 \%$ possuem idade superior a 45 anos. Dentre todos os envolvidos neste estudo $31 \%$ são não-escolarizados, $55 \%$ cursaram o ensino fundamental, $7 \%$ o nível médio e 3,44\% possui o nível superior. Portanto é um grupo com baixo nível de escolaridade.

$\mathrm{Na}$ amostragem $96 \%$ possuem fonte de renda fixa e $76 \%$ percebe de um a quatro salários mínimos, mensais. Os demais declararam que o teto máximo da renda mensal correspondente a 15 salários. Atualmente $90 \%$ dessas pessoas são aposentadas. Destas, homens (11) e mulheres (15) dispōem de tempo integral para convívio no espaço da moradia e para a realizaçáo de atividades relacionadas, principalmente, com a administraçáo e manejo do quintal. Dentre as suas atividades cotidianas se dedicam ao cultivo de plantas. Os informantes que exercem atividades externas ao domicílio, estáo vinculados ao serviço público estadual. Os entrevistados demonstraram que conhecem e utilizam, preferencialmente, plantas introduzidas de outras regiôes do Brasil (exóticas) e com menor ênfase aparecem as espécies que se desenvolvem 
espontaneamente ou são naturais da cobertura vegetal da regiáo.

A área disponibilizada para o cultivo apresentou variaçóes de proporção em relaçáo à área total do terreno do domicílio. A extensão territorial de $97 \%$ dos lotes varia entre $200-1000 \mathrm{~m}^{2}$ e a área cultivada é de $30-575 \mathrm{~m}^{2}$. O maior número de espécies cultivadas em um mesmo quintal foi de 209 as quais são manejadas em $102 \mathrm{~m}^{2}$. A maior área estudada possui $3.750 \mathrm{~m}^{2}$ sendo a única cultivada com a finalidade comercial e que abriga 59 espécies estabelecidas em $3.450 \mathrm{~m}^{2}$ manejados. Em face à extensão territorial de $75 \%$ dos domicílios medir de 200 a $500 \mathrm{~m}^{2}$, predomina o cultivo de espécies herbáceas. Segundo a percepção dessa população esse é um fator limitador para o cultivo de espécies arbóreas nos quintais, principalmente por oferecerem riscos à estrutura das edificaçóes; "eu gosto de árvores de sombra, mas a raiz acaba derrubando a minha casa e do vizinho também. Já tive que derrubar uma mangueira por esse motivo" (69, E.C.). Desse modo pode-se afirmar que o número de espécies cultivadas está mais diretamente relacionado ao interesse e necessidade do proprietário aliados à arquitetura e porte das espécies e sob influência do espaço territorial disponível para o cultivo de plantas.

\section{COMPOSIÇÃO FLORÍSTICA DOS QUINTAIS, POTENCIALIDADES E UTILIZAÇÃO}

A composição florística estabelecida nos quintais estudados corresponde a 397 plantas indicadas localmente com denominaçóes distintas que equivalem a etnovariedades. $\mathrm{O}$ acervo botânico correspondente a estas etnovariedades reúne 275 táxons pertencentes a 79 famílias. Estão identificadas respectivamente nos seguintes níveis: 240 espécies, 34 até o nível de gênero, quatro em nível de família e uma não identificada (Tabela 1, anexada). As famílias com maior número de táxons estão representadas no gráfico a seguir (Figura 2). Outras 35 famílias botânicas estão representadas por uma espécie e 13 famílias com duas.

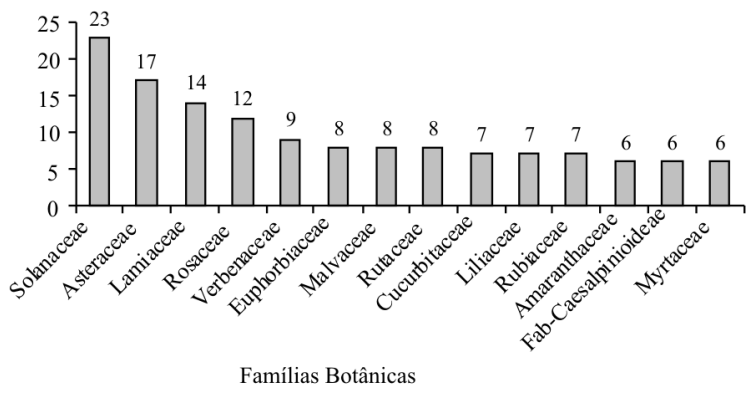

Figura 2 - Famílias Botânicas destacadas com maior número de taxa de cada.

Disposto em diferentes estratos, o componente vegetal presente nos quintais de Mirassol D' Oeste é constituído por plantas pertencentes a seis hábitos sendo: arbóreas, arbustivas, subarbustivas, herbáceas, trepadeiras e epífitas. Os espécimes estão estabelecidos em íntima interação cobrindo a área cultivada na maioria dos domicílios. Em todos os quintais foram registradas plantas dos quatro primeiros hábitos citados e dentre estes o maior número de etnoespécies (130) pertencem às herbáceas (eretas e rastejantes). Para as plantas epífitas e trepadeiras foram catalogadas respectivamente sete e 23 taxa. Estas plantas cobrem o espaço vertical e horizontal associadas, principalmente, espécies arbóreas, arbustivas e subarbustivas. Cada nível do estrato vegetal parece estar disposto sem nenhum vínculo com funçôes que estes possam exercer no conjunto da paisagem ou de necessidades dos seus empreendedores. No entanto, reflete a percepção de arquitetura paisagística daqueles que manejam o local, aliada à disponibilidade de espaço para o cultivo.

Nesse contexto, homens e mulheres conhecem e cultivam plantas pertencentes a 19 categorias locais de uso (etnocategorias) correspondentes a 11 categorias de utilização, largamente conhecidas como de uso comum. Contudo, há uma distinção entre os conhecimentos. As mulheres são especialistas no que se refere às espécies ornamentais e o respectivo manejo, enquanto que os homens consideramse especializados no cultivo de plantas alimentares. As demais categorias são de domínio comum aos dois gêneros Constatou-se, alta diversidade na composição vegetal destes quintais, e que as plantas introduzidas de outras regióes do país, conhecidos e cultivados por essa populaçáo corresponde a aproximadamente $91 \%$ dos taxa indicados. Isto pode ser explicado pelo fato de $100 \%$ dos entrevistados serem migrantes cujo contato com a composiçáo florística natural da regiáo em que residem é pouco comum.

Cada espécime é plantado e manejado em função dos atributos que provê à população. Dentre as 19 categorias locais de uso das plantas, indicadas pela população estudada, as três principais são: ornamental e alimentação humana com cerca de 35\% das citaçôes cada, seguidas da medicinal com 29\% da preferência dessa população. Resultados semelhantes em relação às principais categorias foram registrados em Mato Grosso por Carniello et al. (2003), Santos (2004), Pasa et al. (2005) e em outras regióes do Brasil (Albuquerque e Andrade, 2002). Comparando-se a hierarquia de preferência dessas mesmas categorias, Santos (2004) registrou em Alta Floresta resultados semelhantes aos de Mirassol D'Oeste para as utilizaçôes alimentar e ornamental. Por outro lado, Pasa et al. (2005) registraram em quintais da comunidade de ConceiçãoAçú, na baixada Cuiabana, MT, a utilização alimentar como principal seguida da medicinal, enquanto a ornamental diverge dos resultados descritos acima, ocupando o terceiro nível de importância e com o menor número de espécies no universo conhecido naquela comunidade. Amorozo (2002a) afirma 
que em cidades industrializadas, do interior de São Paulo, a potencialidade ornamental é a principal.

As semelhanças registradas entre Mirassol D'Oeste e Alta Floresta consubstanciadas por intermédio do componente vegetal, e em face das interaçóes estabelecidas por essas populaçôes humanas na sua relação com os recursos naturais, podem estar associadas a duas características comuns entre ambas: a origem da população das regióes sul e sudeste, e a ocupação do espaço caracterizada como urbano industrial. Estas características são bastante distintas da realidade encontrada por Pasa et al. (2005), onde a comunidade apresenta certo isolamento em relação à área urbana e as plantas mais utilizadas são nativas e empregadas para atender necessidades de subsistência, (alimento e remédio), enquanto o estético (ornamental) praticamente não é enfatizado. Entretanto, nessa mesma comunidade, no acervo de espécies medicinais estão presentes espécies introduzidas. Para os autores acima citados isto se deve à influência dos imigrantes na constituiçấo do acervo de espécies conhecidas e amplamente utilizadas atualmente.

A entrada e o estabelecimento de plantas exóticas em Mato Grosso são seculares. Estima-se que tenha se efetivado um processo semelhante ao ocorrido em outras partes do país com a chegada de europeus, africanos e asiáticos que trouxeram consigo recursos vegetais intrínsecos às respectivas culturas (Albuquerque 2002; Viera e Alves 2003). Nos relatos de viajantes e em registro de expediçóes científicas que irromperam por terras mato-grossenses, ainda no século XIX, foram catalogadas espécies exóticas (Saddi 1993; Amorozo 2002b). Mais recentemente o fluxo migratório tem se intensificado e com este, a entrada de propágulos que acompanham a população migrante.

As categorias de uso como: alimentação animal, tóxica, inseticida natural, oleaginosa, mística, assepsia, artesanato e refúgio de avifauna fazem parte do domínio de conhecimento da população mirassolense, porém foram pouco expressivas, aparecendo com uma a duas citaçóes cada. Em Mirassol D'Oeste, a categoria alimentação humana é percebida de maneira detalhada e a ênfase é dada à forma de preparo do alimento e consumo do produto caracterizado como fonte nutricional. Especial atenção constatou-se em relação às plantas prediletas e consumidas pelas crianças. As plantas cultivadas com a finalidade alimentícia reuniram o maior número de categorias de uso local (etnocategorias). O principal critério de classificação dessas categorias adotado por esta populaçáo está associado à forma de preparo para o consumo. Santos (2004) encontrou critérios semelhantes no norte de Mato Grosso, porém descreveu o maior número de etnocategorias para as plantas medicinais.

Essa população cultiva espécies cuja categoria de uso está claramente definida. As potencialidades diagnosticadas no presente estudo estão apresentadas na tabela 2 , com a respectiva correspondência da categoria de uso e as categorias locais (etnocategorias).

Tabela 2 - Correspondência entre catergorias de uso, etnocategorias indicadas e número de citações. Legenda: UE=número de taxa de utilização exclusiva; $\mathrm{EM}=$ número de taxa com indicação multifuncional.

\begin{tabular}{|c|c|c|c|c|}
\hline \multirow{2}{*}{ Categoria de uso } & \multirow{2}{*}{ Etnocategorias } & \multicolumn{3}{|c|}{ №. de Citações } \\
\hline & & Total & UE & EM \\
\hline Alimentação Humana & $\begin{array}{c}\text { Come a fruta } \\
\text { Come cozido } \\
\text { Toma o chá (não é remédio) } \\
\text { Toma o suco } \\
\text { Come a salada } \\
\text { Come curtido } \\
\text { Tempero } \\
\text { Criança come }\end{array}$ & 113 & 82 & 31 \\
\hline Alimentação Animal & Animal come & 02 & 00 & 02 \\
\hline Medicinal & Remédio & 102 & 64 & 38 \\
\hline Tóxica & Veneno & 01 & 00 & 01 \\
\hline Inseticida Natural & Veneno caseiro & 01 & 01 & 00 \\
\hline Uso Místico & $\begin{array}{l}\text { Proteção do lar, } \\
\text { Uso espiritual }\end{array}$ & 02 & 00 & 02 \\
\hline Oleaginosa & Fabrica óleo & 01 & 00 & 01 \\
\hline Artesanato & Faz rosários e colares & 01 & 00 & 01 \\
\hline Assepsia & Banhos & 01 & 00 & 01 \\
\hline Refúgio de avifauna & Deixa porque passarinho gosta & 02 & 00 & 02 \\
\hline
\end{tabular}


Dentre os 275 táxons cultivados pelos mirassolenses cerca de $80 \%$ possuem as potencialidades citadas anteriormente compreendendo utilização exclusiva de uma finalidade para cada espécie.

Dentre as plantas ornamentais, $86 \%$ são cultivadas exclusivamente para o embelezamento do domicílio, enquanto que entre as alimentares, em torno de $72 \%$ são destinadas especificamente para fins nutricionais.

Outras 46 espécies foram indicadas como multifuncionais destacadas com duas a quatro formas de utilização. 59\% destas reúnem as funçôes alimentar e medicinal, sendo a alimentar o principal atributo. Brito (1996), registrou 6\% das espécies como multifuncionais, em quintais de Aripuanã, MT, enquanto Santos (2004), em Alta Floresta e Pasa et al. (2005), em Conceição-Açu registram resultados muito próximos aos obtidos em Mirassol D’Oeste, (16\%).

A arruda (Ruta graveolens L.), para os envolvidos nessa pesquisa é a única espécie com quatro indicaçóes: medicinal, assepsia, ornamental e mística. Para coroa-de-cristo (Euphorbia milii Des Moul.), conta-de-lágrima (Coix lacryma-jobi L.) e romã (Punica granatum L.) foram indicadas três funçóes simultâneas sendo que a medicinal e a ornamental são comuns a todas. As espécies indicadas de uso espiritual (místico) como guiné (Petiveria alliacea L.), fonte de alimentação animal como caruru (Amaranthus deflexus L.), e as percebidas como importantes locais de refúgio para avifauna como rabo-de-gato (Pachystachys lutea Ness) foram associadas a outras formas convencionais de utilização.
As plantas de maior freqüência nos quintais mirassolenses constam na tabela 3. São 34 espécies indicadas nos dez primeiros níveis de preferência dessa comunidade. Em parte, o cultivo nos quintais de Mirassol D'Oeste está associado ao consumo e à necessidade da população, corroborando com o que Saragoussi et al. (1990) descreveram em relação a três comunidades na Amazônia, caracterizando o quintal como um importante espaço na complementação da alimentação e renda familiar. Apresentam uma sazonalidade dos cultivos ao longo do ano em conformidade com as condiçôes climáticas, locais.

Em 27 domicílios, dentre os 29 estudados, as plantas cultivadas contribuem no orçamento familiar em dois aspectos: reduzindo a compra de legumes e frutos, visto que são produzidos no quintal e também pela troca ou venda do excedente dessa produção. O depoimento a seguir elucida essa afirmação: "alguma coisa ajuda, limão para temperar, milho, abóbora, jabuticaba, banana e algumas plantas como remédio, aproveita tudo que tem, se planta bastante colhe bastante, se planta pouco colhe pouco, e evita procurar nas casas dos outros e comprar no mercado" (77, M. S. do S.P.). A afirmaçáo seguinte reflete a relevância das plantas na complementaçáo econômica familiar: "Ajuda bastante, com as plantas da horta, economizo muito, salsinha, cebolinha, coentro não preciso comprar. Nunca fiquei sem cebolinha na minha casa" (52, M. das G.R. da S.).

Somente em um domicílio de classe média baixa (maior renda declarada), o produto procedente do quintal não é

Tabela 3 - Relação das espécies mais importantes para a população, presentes nos quintais. Legenda: $\mathrm{Nl}=$ nível de importância; Fa= Freqüência absoluta; $\mathrm{Fr}=$ Freqüência relativa; $\mathrm{Pl} .=$ Potencialidade indicada; $\mathrm{md}=$ medicinal; or = ornamental; $\mathrm{al}=$ alimentar.

\begin{tabular}{|c|c|c|c|c|c|}
\hline $\mathrm{NI}$ & Taxa & Nome Local & $\mathrm{Fa}$ & $\operatorname{Fr}(\%)$ & P.I. \\
\hline $1^{0}$ & Allium fistulosum $\mathrm{L}$. & Cebolinha & 26 & 89,65 & al \\
\hline $2^{0}$ & Carica papaya L. & Mamão & 23 & 79,31 & al \\
\hline $3^{0}$ & Cereus peruvianus (L.) J.S. Muell. & Mandacaru & 22 & 75,86 & $\mathrm{md}$ \\
\hline $4^{0}$ & Aloe vera (L.) Burm. f. & Babosa & 20 & 68,96 & $\mathrm{md}$ \\
\hline \multirow{3}{*}{$5^{0}$} & Malpighia glabra L. & Acerola & 20 & 68,96 & al \\
\hline & Annona squamosa L. & Pinha & 19 & 65,51 & al \\
\hline & $\begin{array}{c}\text { Dypsis lutescens (H. Wendl.) Beentje \& J. } \\
\text { Dransf }\end{array}$ & Coqueirinho & 19 & 65,51 & or \\
\hline \multirow{5}{*}{$6^{0}$} & Cocos nucifera L. & Coco-da-baia & 18 & 62,06 & $\mathrm{al} / \mathrm{md}$ \\
\hline & Myrciaria cauliflora (Mart.) 0. Berg. & Jabuticaba & 18 & 62,06 & al \\
\hline & Phyllanthus tenellus Roxb. & Quebra-pedra & 18 & 62,06 & $\mathrm{md}$ \\
\hline & Petiveria alliacea L. & Guiné, guiné-da-índia, gambá & 18 & 62,06 & $\mathrm{md} / \mathrm{mt}$ \\
\hline & Rosa × grandiflora Lindl. & Roseira-vermelha & 18 & 62,06 & or \\
\hline
\end{tabular}


Tabela 3 - Continuação.

\begin{tabular}{|c|c|c|c|c|c|}
\hline $\mathrm{NI}$ & Taxa & Nome Local & $\mathrm{Fa}$ & $\operatorname{Fr}(\%)$ & P.I. \\
\hline \multirow{6}{*}{$7^{0}$} & Capsicum chinense Jacq. & Pimenta-bode & 17 & 58,62 & al \\
\hline & $\begin{array}{c}\text { Dysphania ambrosioides (L.) Mosyakin \& } \\
\text { Clemants }\end{array}$ & Erva-de-sta-maria & 17 & 58,62 & md \\
\hline & Hydrangea macrophylla(Thumb.) Ser. & Hortência & 17 & 58,62 & or \\
\hline & Plectranthus barbatus Andrews & Boldo & 17 & 58,62 & md \\
\hline & Ruta graveolens L. & Arruda & 17 & 58,62 & $\mathrm{md} / \mathrm{as} / \mathrm{or} / \mathrm{mt}$ \\
\hline & Zingiber officinale Roscoe & Gengibre & 17 & 58,62 & al \\
\hline \multirow{6}{*}{$8^{0}$} & Anacardium occidentale L. & Caju & 16 & 55,17 & al \\
\hline & Dianthus chinensis L. & $\begin{array}{l}\text { Cravo, cravo-branco, cravo-bordô, } \\
\text { vermelho, rosa, amarelo e mesclado }\end{array}$ & 16 & 55,17 & or \\
\hline & Manihot esculenta Crantz & $\begin{array}{c}\text { Mandioca (cacau, } 3 \text { meses, } \\
\text { branquinha) }\end{array}$ & 16 & 55,17 & al \\
\hline & Mentha pulegium L. & Poejo & 16 & 55,17 & md \\
\hline & Psidium guajava L. & Goiaba & 16 & 55,17 & $\mathrm{al} / \mathrm{md}$ \\
\hline & Zinnia elegans Jacq. & $\begin{array}{l}\text { Capitão, bem-me-quer, capitão- } \\
\text { vermelho, capitão- amarelo }\end{array}$ & 16 & 55,17 & or \\
\hline \multirow{6}{*}{$9^{\circ}$} & Anthurium × froebelii Hort. & Antúlio-cor-de-rosa & 15 & 51,72 & or \\
\hline & Chlorophytum comosum (Thunb.) Jacques & Folhaginha-folhas-fininhas & 15 & 51,72 & or \\
\hline & Curcuma longa L. & Açafrão & 15 & 51,72 & $\mathrm{al} / \mathrm{md}$ \\
\hline & Ixora coccinea L. & Ixória-vermelha & 15 & 51,72 & or \\
\hline & Mangifera indica L. & $\begin{array}{l}\text { Manga, mangueira, (manga- } \\
\text { bourbom, manga-espada, manga- } \\
\text { coquinho, manga-de-quilo) }\end{array}$ & 15 & 51,72 & al \\
\hline & Syagrus oleracea (Mart.) Becc. & Palmito-amargo, gueirova & 15 & 51,72 & al \\
\hline \multirow{4}{*}{$10^{\circ}$} & Duranta repens L. & Pingo-de-ouro & 14 & 48,27 & or \\
\hline & Polypodium decumanum Willd. & Samambaia-de-coqueiro & 14 & 48,27 & or \\
\hline & Punica granatum L. & Romã & 14 & 48,27 & $\mathrm{al} / \mathrm{md} / \mathrm{or}$ \\
\hline & Rosmarinus officinalis L. & Alecrim & 14 & 48,27 & md \\
\hline
\end{tabular}

considerado como um incremento na renda da família. Entretanto, um estudo piloto realizado em um dos quintais cultivados, cujo proprietário percebe renda mensal em torno de 3,5 salários mínimos, comprovou-se que o complemento pode atingir de 3 a $5 \%$ do orçamento familiar ao longo do ano. Para $7 \%$ dessa população, os produtos vegetais cultivados no quintal estão incorporados no consumo cotidiano, de maneira tão natural que passam despercebidos como um incremento na economia doméstica. $\mathrm{O}$ produto resultante do cultivo em quintais de Mirassol D' Oeste é reconhecido como um importante complemento na dieta alimentar de
93\% das famílias, sendo que para 58\% foi avaliado como imprescindível. A afirmação a seguir evidencia que para parte dessa populaçáo o cultivo e o aproveitamento dos produtos do quintal estão associados não somente ao poder aquisitivo e/ou necessidade de incremento na dieta da família, mas ao conhecimento e aptidão para o cultivo de plantas: "A gente nota, e isso vejo há muitos anos têm pessoas que não tem necessidade de ficar plantando no quintal, poderia comprar tudo no mercado, na feira, está em situação boa. Mas é que cresceu vendo e ajudando plantar e hoje prefere as frutas e as verduras que ele conhece desde a semente e a muda. Já 
em outros casos dá pra perceber que são pessoas necessitadas e não plantam nada ao redor de casa. Fica aquele 'terrenão' (solo fértil) sem proveito. Os motivos, a gente náo sabe muito bem quais são, mas só a parte financeira eu acho que não é" (69, E.C.).

Em torno de $17 \%$ dos quintais os moradores manejam plantas nativas com utilização ornamental, na pesca, e medicinal. Espécies como laranjinha (Pouteria glomerata (Miq.) Radlk.), samambaia-de-coqueiro (Polypodium decumanum Willd.), e chapéu-de-couro (Echinodorus grandiflorus (Cham. \& Schltdl.) Micheli), aroeira (Myracrodruon urundeuva Allemão) foram as encontradas nos quintais, em que o período de permanência do morador no local é superior a 20 anos.

A incorporação dessas espécies nos quintais se deve às interaçóes estabelecidas pelos moradores com o ambiente de ocorrência dessas plantas e com pessoas conhecedoras dos respectivos atributos conferidos a estas. Sobre a laranjinha (Pouteria glomerata (Miq.) Radlk.), um entrevistado argumentou: "Esta é planta só daqui, (referindo se a Mato Grosso) veio lá dos lados da fronteira na beira do rio, com um povo daqui. É isca pra pesca e o peixe vem. Foi plantada para ver se brotava, e olha aí o pé crescendo" (52, O.A.P.M.). Manifestaçóes dessa natureza revelam a importância do quintal como um espaço de experimentação sobre cultivo de plantas ainda pouco conhecidas, indissociada da interação dos saberes humanos, que contribui na constituição de um arcabouço de conhecimento, acerca de espécies locais e do meio sobre o qual ele interage direta e indiretamente. Ainda em relação às espécies nativas, em Mirassol D' Oeste a aroeira obteve uma indicação, como medicamento, enquanto que em Porto Limão, uma comunidade tradicional na fronteira do Brasil com a Bolívia, essa espécie foi citada com o maior índice de importância medicinal para a população local, tanto pelos múltiplos usos quanto pelo número de citaçóes (Cabral e Carniello 2004). As espécies nativas aqui tratadas, também foram catalogadas entre as multifuncionais e de intensa utilização, pela população Cacerense que é, em sua maioria, nativa da região. Constatou-se ainda que em $67 \%$ dos quintais dessa população, as plantas nativas estão presentes e com funçôes definidas. (Carniello et al., 2003). Desse modo pode-se inferir que as interaçóes estabelecidas entre populaçóes migrantes e locais podem possibilitar o acesso de ambos a conhecimentos recíprocos sobre plantas presentes nos fragmentos locais e também sobre as introduzidas de outras regióes por intermédio do fluxo migratório da população.

Dentre os taxa apresentados na tabela 3, 8\% são considerados nativos por essa população. Dois são plantas espontâneas cosmopolitas: o quebra-pedra (Phyllanthus tenellus Roxb.) e a erva-de-santa-maria (Dysphania ambrosioides (L.) Mosyakin \& Clemants). Ambos constam em estudos realizados em diversas regióes do Brasil. Também se registrou nos quintais as espécies: espeteiro-do-mato (Casearia sylvestris Sw.) e jatobá-do-cerrado (Hymenaea stigonocarpa Mart. ex Hayne).

Se por um lado o alto número de espécies introduzidas pelos migrantes contribui com a disseminação e diversificação do componente vegetal em território mato-grossense por outro, o baixo número de espécies nativas conhecidas e utilizadas por essa população, é um indicador de que a maioria destes ainda não estabeleceu uma identidade com as plantas locais. Isto pode acarretar a substituição de espécies nativas por exóticas introduzidas devido ao valor (simbólico e utilitário) atribuído às espécies pertencentes à essa categoria. As últimas consubstanciam um acervo de recursos vegetais e conhecimento intrínseco, que acompanham essa população ao logo de décadas. Guarim Neto e Moraes (2003) alertam para o problema do desconhecimento das plantas do cerrado associado à acelerada devastação deste bioma genuinamente brasileiro, que ocupa parte do território no qual está inserido o município de Mirassol D’Oeste.

Outro aspecto que favorece a manutenção e status de conhecimento apresentado acima é a estreita relação desses migrantes com as suas regióes de origem, reproduzindo em quintais mato-grossenses réplicas de quintais do sul e sudeste do Brasil, inclusive com espécies típicas. Em um deles foram catalogadas espécies como: araucária (Araucaria sp.), ameixa (Prunus domestica L.), cereja (Prunus sp.), morango (Fragaria sp.), nêspera (Eriobotrya japonica (Thunb.) Lindl.), salvia (Salvia officinalis L.), consorciadas a uma grande quantidade de plantas ornamentais, adquiridas em floriculturas. Neste caso a informante apresentou as espécies mencionadas acima, todas comuns do seu Estado de origem, ao mesmo tempo em que manifestava a satisfação com a aquisição e o manejo do quintal assim constituído. As plantas e demais elementos presentes no quintal promovem a ligação do cotidiano desta família com o seu local de origem e contribuem na manutençáo de características culturais por intermédio do manejo adotado. Contexto similar foi registrado em outros quintais de migrantes da região sudeste. Manifestaçóes como as descritas acima revelam o sentimento afetivo e a percepção desses seres humanos em relação aos seus locais de origem. Este sentimento de estreita relação com o local de origem e reprodução da cultura a qual um povo está filiado é conceituado por Tuan (1980), como topofilia compreendendo uma íntima relação estabelecida entre seres humanos com o seu lugar de origem.

Em todos os quintais, as plantas nativas com maior aceitação são as samambaias, tendo maior representação a espécie Polypodium decumanum Willd. (samambaia-decoqueiro) que ocupa o $10^{\circ}$ nível de importância e orquídeas (Cattleya nobilior Rchb. f. e Cyrtopodium paranaenese Schltr.) ambas denominadas por essa população exclusivamente como “orquídea”. Para Rico-Gray et al. (1990), estas evidências 
podem ter como conseqüência uma redução do banco genético de espécies naturais da regiáo.

Segundo Amorozo (2002a), "a fisionomia de quintais e jardins é moldada por combinaçốes e variaçôes de sua estrutura, funçấo e tamanho. Seu conteúdo e seu destino estão firmemente atrelados à sua história, que é a história da família ou famílias que ocuparam o domicílio e refletem situaçôes e experiências vividas por seus membros. Assim, quintais e jardins de migrantes podem conter plantas das regióes de origem, quintais antigos podem estar conservando variedades raras, ou mesmo algumas que havia no ambiente original antes de sua conversão para agricultura extensiva". Consoante com este pressuposto o presente estudo revelou que: limitaçôes econômicas, hábitos alimentares, o cultivo de plantas que simbolizam as respectivas regiôes de origem da populaçấo, os atributos imputados às espécies cultivadas; $\mathrm{e}$, a tradição de manejo agrícola migrados com a população para o espaço urbano são fatores basilares no manejo e manutenção dos quintais de Mirassol D'Oeste.

É pertinente destacar aqui, que na natureza, à medida que uma planta é percebida como de relevância para um dado grupo pode ser poupada em decorrência dos benefícios revertidos aos que a conhecem, porém, nos casos de utilizaçáo excessiva, principalmente com o comércio informal corre o risco de escasseamento e até de extinção. A segunda situação é muito comum a várias espécies da flora brasileira. A poaia (Psychotria ipecacuanha (Brot.), Stokes), base econômica da regiāo da bacia do Alto Paraguai, Mato Grosso, em meados do século passado é um típico exemplo dessa problemática, que para Oliveira e Martins (2002), consiste em erosão genética. Nos quintais estudados ocorre situação inversa. As espécies que gozam de alguma preferência por parte dos moradores são cultivadas como um bem a ser conservado, no próprio quintal sob manejo diferenciado, envolvendo adubação, poda e cultivo de vários espécimes, e distribuição de propágulos para vizinhos e parentes quando estes se interessam. A distribuição dos propágulos funciona como uma alternativa, garantindo a reposição em caso de perda de uma determinada espécie, no próprio quintal. Em Mirassol D' Oeste registrou-se este fato, mais fortemente no manejo de plantas medicinais. Junto à população de Santo Antonio de Leverger, no entanto, essa precauçáo da população foi registrada em relação às variedades de mandioca, (Amorozo, 2002a). Os quintais constituem um relevante espaço pedagógico onde pessoas de diferentes faixas etárias realizam cotidianamente experimentaçôes sobre plantio e manejo de espécies vegetais. Tais práticas possibilitam a construção de conhecimentos, ancorados na história de vida, nas relaçôes estabelecidas com as plantas e com os grupos sociais (vizinhos e parentescos) com os quais compartilham a arte de plantar, colher e conservar.
Com o estabelecimento de uma convivência prolongada com cada unidade física (o domicílio) e familiar (os respectivos responsáveis) no cotidiano, foram revelados naturalmente, aspectos que possibilitaram o registro do acervo de espécies dos quintais de Mirassol D' Oeste, estabelecidos em pequenos espaços. Cada locus é monitorado e manejado à luz do conhecimento do proprietário e familiares engendrado no cotidiano como um bem precioso para a coletividade.

\section{AGRADECIMENTOS}

Aos informantes que compartilharam conosco valiosa sabedoria. À Dra Maria Christina de M. Amorozo pela leitura e sugestôes ao manuscrito. Obrigada!

\section{BIBLIOGRAFIA CITADA}

Albuquerque, U.P.; Andrade, L.H.C. 2002. Traditional botanical knowledge and conservation in an area of caatinga in Pernambuco state, Northeast Brazil. Acta Botanica Brasilica 16(3): 273-285. (in Portuguese, with abstract in English).

Alcorn, J.B. 1997. The scope and aims of ethnobotany in a developing word. In: Schultes, R.E.; Reis, S.V. (Eds.). Ethnobotany Evolution of Discipline. Dioscorides Press, Portland. p. 23-39.

Alexíades, M.N. 1996. Selected guidelines for ethnobotanical research: a field manual. The New York Botanical Garden Press, New York 306p.

Amorozo, M C. M. 1996. The ethnobotanical approach in medicinal plants research. In: Di Stasi, L.C. (Org.) Medicinal plants: Art and Science: a guide to interdisciplinary research. Editora UNESP, São Paulo. p.47-68.(in Portuguese).

Amorozo, M.C.M. 2002a. Traditional agriculture, enduring spaces and the joy of planting. In: Albuquerque, U.P. de; Alves, A.G.C.; Silva, A.C.B.L.; Da Silva, V.A. (Orgs.). Actualities in Ethnobiology and Ethnoecology. Recife: Sociedade Brasileira de Etnobiologia e Etnoecologia. Ed. SBEE, Recife, PE. p. 123-131. (in Portuguese).

Amorozo, M. C.M. 2002b. Use and diversity of medicinal plants in Santo Antonio do Leverger, MT, Brazill. Acta Botanica Brasilica, 16 (2):175-188. (in Portuguese, with abstract in english).

Bernard, H.R.1988. Research methods in cultural anthropology. Sage Publications, Newbury Park, CA. 520pp.

Brasil. Ministry of Health, National Health Foundation 2001. Information system of indigenous health. FUNASA, Cuiabá, Mato Grosso. (in Portuguese).

Brito, M. A. 1996. Social use of biodiversity in agroforestry yards of Aripuanã - Mato Grosso. (Master Dissertation), Universidade Federal de Mato Grosso, Cuiabá, Mato Grosso. 108pp. (in Portuguese, with abstract in english).

Brito, M.A.; Coelho, M.F. 2000. The agroforestry yards at tropical regions - units sustainable in self. Tropical Agriculture Journal 1(1): 7-38. (in Portuguese, with abstract in english). (in Portuguese, with abstract in English). 
Caballero, J. 1979. Ethonobotany. In: Barrera, A. (Ed.). La Etnobotânica: tres puntos de vista y una perspectiva. INIREB, Xalapa. p. 27-30. (in Spnish).

Cabral, C.D.O.; Carniello, M.A. 2004. Use medicinal models of aroeira, Myracrodruon urundeuva Fr. All. at Porto Limão, Cáceres, Mato Grosso. In: 4th Symposium Nature Resources, Economic and Social in Pantanal. - Regional Sustentable. Corumbá, MS. Annals - Corumbá, EMBRAPA-Pantanal. (http:// www.cpap. embrapa.br). Acesso: 14/02/05. (in Portuguese).

Carniello, M.A.; Cabral, C.D.O.; Santos-Silva, R. 2003. Homegardens: spaces of the biodiversity conservatiāo at Cáceres. In: Bezerra, D.O.S; Castrillon, S.K.I. (Orgs.). Environmental and social basis for urban plan of the Cáceres city, Mato Grosso. Unemat/ FAPEMAT, Cáceres, Mato Grosso. p. 30-33. (in Portuguese).

Cronquist, A. 1981. An integrated system of classification of flowering plants. Columbia University Press, New York. 1.262pp.

Ferreira, M.S.F.D.; Dias, F.M.S. 1993. Comparison of the usage of space for yards in two neighborhoods at Cuiabá municipalityMT. In: Annals of 4th National Symposium of Environment Studies, 1993, Cuiabá, Mato Grosso. p. 83-91. (in Portuguese, with abstract in english).

Freire, A.G.; Melo, M.N.; Silva F.S.; Silva, E. 2005. In the surroundings of home and animals in homegarden. Agricultures, 2: 20-23. (in Portugues).

FIBGE (Brazilian Institute of Geography and Statistics). 1992. Technical Manual of Brazilian Vegetation - Geosciences Research methods - Manual. Vol 1. IBGE, Rio de Janeiro. 92 pp. (in Portuguese).

FIBGE (Brazilian Institute of Geography and Statistics). 2005. Municipal Social Indicators: An Analysis of the results of Census 2000, Brazil and Major Regions. (http://www.ibge.gov.br). Acessed:11/01/05. (in Portuguese).

Guarim Neto, G.; Morais, R.G. 2003. Medicinal plants resources in the Cerrado of Mato Grosso State, Brazil: a review. Acta Botanica Brasilica, 17(4):561-584. (in Portuguese, with abstract in english).

Kumar, B.M.; Nair, P.K.R. 2004. The enigma of tropical homegardens. Agroforestry Systems, 61:135-152.

Ludke, M.; André, M.E.D.A. 1986. Research in Education: qualitative approaches. EPU, São Paulo, SP. 99pp. (in Portuguese).

Martin, G.J. 1995. Ethnobotany - a methods manual. Chapman \& Hall, Londres. 268pp.

Martins, A.L.U. 1998. Homegardens Urban in Manaus: organization, space and plant resources in the neighborhood Jorge Teixeira. (Master Dissertation), Centro de Ciências do Ambiente/Universidade do Amazonas, Manaus, Amazonas. 79pp. (in Portuguese, with abstract in English).

Ming, L.C. 1996. Collection of Medicinal Plants. In: Di Stasi, L.C. (Org.). Medicinal plants: Art and Science: a guide to interdisciplinary research. Editora UNESP, São Paulo. p. 69-86. (in Portuguese).

Miranda, L.; Amorim, L. 2001. Mato Grosso: geographical atlas. Entrelinhas, Cuiabá, Mato Grosso. 40pp. (in Portuguese).
Moran, R.C. 1995. Key to ferns families. In: Davidse,G.; Souza, M.S.; Knapp, S. (Eds.). Flora Mesoamericana. Vol. I. Psilotaceae a Salviniaceae. Universidad Nacional Autónoma de México, México, DF. p. 1-2. (in Spanish).

Noda, H.; Noda, S.N. 2003. Traditional familiar agriculture and conservation of socio-Amazonian biodiversity. Interaçōes Interncional Journal of Local development, 4(6): 55-66. (in Portuguese).

Oakley, E. 2004. Homegardens: a cultural responsibility. Agroforestry Systems 1 (1): 37-39. (in Portuguese).

Oliveira, L.O.; Martins, E.R. 2002. A quantitative assesment of genetic erosion in ipeca (Psycotria ipecauanha). Genetic Resources and Crop Evolution, 49: 607-617.

Pasa, M.C.; Soares, J.J.; Guarim-Neto, G. 2005. Ethnobotany study in community of Conceição-Açu (on the upper basin of the River Aricá Açu, MT, Brazil). Acta Botânica Brasílica, 19 (2):195-207. (in Portuguese, with abstract in english).

Prance, G.T. 2000. Ethnobotany and the future of conservation. Biologist, 47(2): 65-68.

Ribeiro, J.E.L. da S.; M.J.G. Hopkins; A. Vicentini; Sothers, C.A.; Costa, M.A. da S.; Brito, J.M.; Souza, M.A.D. de; Martins, L.H.P.; Lohmann, L.G.; Assunção, P.A.C.L.; Pereira, E. da C.; Silva, C.F. da; Mesquita, M.R. e Procópio, L.C.. 1999. Flora of Reserva Ducke - Identification guide of vascular plants from an terra firme forest in Central Amazonia INPA-DFID. 816pp. (in Portuguese).

Rico-Gray, V.; Garcia-Franco, J.G.; Chemas, A.; Puch, A.; Sima, P. 1990. Species, composition, similarity, and structure of Mayan Homegardens in Tixpeaul and Tixcacaltuyub, Yucatán, México. Economic Botany, 44 (4): 470-487.

Saddi, N. 1993. The observations of Riedel, Langsdorff Botanical Expedition, Mato Grosso (Brazil), in the Manuscript D'Alincourt. In: Costa, M.F.G. (Org.) Traveling between manuscripts Langsdorff and D'Alincourt. Ed. Universitária, Cuiabá. p. 36-49. (in Portuguese).

Santos, S. 2004. An ethnoecological study of homegardens at Alta Floresta municipality- - MT. (Master Dissertation), Instituto de Biociências/Universidade Federal de Mato Grosso, Cuiabá, Mato Grosso. 167pp. (in Portuguese, with abstract in English).

Saragoussi, M.; Martel, J.H.L.; Ribeiro, G. 1990. A Comparison of yard compositions in three localities of terra firme in the State of Amazonas. In: Posey, D.A.; Overal, W.L.; Clement, C.R.; Plotkin, M.J; Elisabetsk, E; Da Mota, C.N.; Barros, J.F.P.I.L. (Org.). Ethnobiology: implications and applications. Vol. 2. CNPq/ Museu Goeldi, Belém. p. 295 -303. (in Portuguese).

SEPLAN - State Government of Mato Grosso - Zoning / Map Server - Ministry of Planning and General Coordination Superintendence of Information - SEPLAN - SINF. (http:// www.seplan.mt.gov.br) Acessed: February, 02, 2005. (in Portuguese).

Finance Department of Mirassol D 'Oeste municipality,MT - Department of Real Estate Cadastre - Database updated in January 2006 - Printed version. February, 14, 2006. (in Portuguese). 
Silva, L.O. 2004. Homegardens: the backyard and brasilian dwellinghouses. Cadernos de Arquitetura e Urbanismo. Belo Horizonte, 11(12): 61-78. (in Portuguese, with abstract in english).

Soemarwoto, O.; Conway, G.R. 1992. The javanese homegarden. Jornal for forming systems research-extension, 2(3): 95-118.

Souza, V.C.; Lorenzi, H. 2005. Systematic Botany: a illustraded guide to the identification of families to Angiosperms Brazillian Flora - APG II based. Instituto Plantarum, Nova Odessa, São Paulo. 640p. (in Portuguese).

Stivens, P. F. Angiosperm Phylogeny Website. (http://www.mobot. org/MOBOT/reserch/APweb/). Acesso: November, 18, 2005.
Tuan, Y.F. 1980. Topophilia: a stude of perception, attitudes and values of environment. DIFEL, São Paulo. 288pp. (in Portuguese).

Vieira, R.F.; Alves, R.B.N. 2003. Challenges for the conservation of genetic resources of medicinal and aromatic plants in Brazil. In: Cole, MF, Costa Junior, P.; Dombroski, JLD (Orgs.). Different views on ethnobiology, ethnoecology and medicinal plants. Unicem publicaçóes, Cuiabá. p. 121-136. (in Portuguese).

Recebido em 23/11/2007

Aceito em 14/12/2009

Anexo 1 - Tabela 1 - Plantas encontradas nos quintais de Mirassol D’Oeste, MT. Legenda: Ref.= número de coleta (Carniello, M. A. et al.), \#=número de tombo no HRCB, il=identificada no local e fotografada; $\mathrm{Nc}=$ número de citações para a planta; $\mathrm{Hb}=$ hábito: ar=arbóreo, hb=herbáceo, at=arbustivo, sa=subarbustivo, ep=epífito, tr=trepador (lianas e cipós), pr=prostrado; $\mathrm{Pi}=$ potencialidade indicada: al=alimentação humana, aa=alimentação animal, md=medicinal, or=ornamental, $\mathrm{mt}=$ mística, $\mathrm{ar}=$ artesanato, is=inseticida natural, ol=oleaginosa, as=assepsia, $\mathrm{ra}=$ refúgio da avifauna, $\mathrm{tx}=$ =tóxica; $\mathrm{pni}=\mathrm{potencialidade}$ não indicada; ni=sem denominação local; *'sensu Cronquist, (1981).

\begin{tabular}{|c|c|c|c|c|c|}
\hline Nome Científico & Denominação Local & Nc & $\mathrm{Hb}$ & $\mathrm{Pi}$ & Ref. \\
\hline \multicolumn{6}{|l|}{ Acanthaceae } \\
\hline Crossandra infundibuliformis Nees & Cossadro & 11 & at & or & 137 \\
\hline Justicia brandegeana Wassh. \& L. B. Sm. & Erva-cidreira-de-folha & 12 & hb & md, al & 164 \\
\hline Odontonema strictum (Nees) Kuntze & Junta-de-grilo & 2 & at & or & 156 \\
\hline Pachystachys lutea Nees & Camarão-amarelo, rabo-de-gato, enfeito & 3 & at & or, ra & 132 \\
\hline \multicolumn{6}{|l|}{ Adoxaceae } \\
\hline Sambucus australis Cham. \& Schltdl. & Sabugueiro & 6 & at & md & 149 \\
\hline \multicolumn{6}{|l|}{ Alismataceae } \\
\hline Echinodorus macrophyllus (Kunth) Micheli & Chapéu-de-couro & 4 & hb & md & 2.565 \\
\hline \multicolumn{6}{|l|}{ Amaranthaceae } \\
\hline Alternanthera dentata (Moench) Stuchlik ex. R.E. Fr. & Terramicina & 6 & hb & md & 178 \\
\hline Amaranthus deflexus $\mathrm{L}$. & Caruru & 3 & hb & al, aa & 498 \\
\hline Beta vulgaris L. & Beterraba & 1 & hb & al & il \\
\hline Celosia argentea L. & Crista-de-galo, crista-de-galo-mini & 7 & hb & or & 131 \\
\hline C. cristata L. & Crista-de-galo & 2 & hb & or & 190 \\
\hline Dysphania ambrosioides (L.) Mosyakin \& Clemants & Erva-de-santa-maria, menstruz & 17 & $\mathrm{hb}$ & $\mathrm{al}, \mathrm{md}$ & 373 \\
\hline \multicolumn{6}{|l|}{ Amaryllidaceae } \\
\hline Hippeastrum striatum (Lam.) H.E. Moore & Sucena-do-campo, lírio & 3 & hb & or & 485 \\
\hline $\begin{array}{l}\text { Scadoxus multiflorus (Martyn) Raf. subsp. katherinae (Baker) } \\
\text { Friis \& Nordal }\end{array}$ & $\begin{array}{l}\text { Coroa-de-anjo-rosa, coroa-imperial, coroa- } \\
\text { de-finados }\end{array}$ & 4 & $\mathrm{hb}$ & or & il \\
\hline \multicolumn{6}{|l|}{ Anacardiaceae } \\
\hline Anacardium occidentale L. & Caju & 16 & $a b$ & al & 198 \\
\hline Mangifera indica L. & $\begin{array}{l}\text { Manga, mangueira, (manga-bourbom, manga- } \\
\text { espada, manga-coquinho, manga-de-quilo) }\end{array}$ & 15 & $a b$ & al & $41.908^{\#}$ \\
\hline Myracrodruon urundeuva Allemão & Aroeira, árvore-aroeira & 1 & $a b$ & md & 51 \\
\hline Spondias cythera Tussac & Cajamanga & 2 & $a b$ & al & il \\
\hline S. purpurea L. & Seriguela & 2 & $a b$ & al & il \\
\hline \multicolumn{6}{|l|}{ Annonaceae } \\
\hline Annona squamosa L. & Pinha & 19 & $a b$ & al & il \\
\hline Apiaceae & & & & & \\
\hline
\end{tabular}


Anexo 1 - Tabela 1 - Continuação.

\begin{tabular}{|c|c|c|c|c|c|}
\hline Nome Científico & Denominação Local & Nc & $\mathrm{Hb}$ & $\mathrm{Pi}$ & Ref. \\
\hline Coriandrum sativum L. & Coentro & 8 & hb & $\mathrm{al}, \mathrm{md}$ & 182 \\
\hline Eryngium foetidum $\mathrm{L}$. & $\begin{array}{l}\text { Coentro-bravo, coentro, coentro-da-folha- } \\
\text { larga, coentro-japonês }\end{array}$ & 2 & hb & al & 489 \\
\hline Foeniculum vulgare Mill. & Erva-doce & 9 & $\mathrm{hb}$ & $\mathrm{al}, \mathrm{md}$ & 129 \\
\hline Petroselinum crispum (Mill.) Nyman ex A. W. Hill & Salsinha, salsa, salsa-de-cheiro & 11 & $\mathrm{hb}$ & al & il \\
\hline \multicolumn{6}{|l|}{ Apocynaceae } \\
\hline Allamanda cathartica L. & Papoula & 1 & $\operatorname{tr}$ & or & 372 \\
\hline A. blanchetii A. DC. & Papoula-bordo & 1 & $\operatorname{tr}$ & or & 187 \\
\hline Catharanthus roseus (L.) G. Don & Boa-noite, bom-dia & 4 & $\mathrm{hb}$ & & 136 \\
\hline Nerium oleander $\mathrm{L}$. & Espirradeira-cor-de-rosa & 3 & at & or & 196 \\
\hline Tabernaemontana coronaria (Jacq.) Willd. & Jasmim & 10 & at & or & 389 \\
\hline \multicolumn{6}{|l|}{ Araceae } \\
\hline Anthurium $\times$ froebelii hort. & Antulio-vermelho & 8 & $\mathrm{hb}$ & or & 378 \\
\hline Colocasia esculenta L. & $\begin{array}{l}\text { Inhame (clones branco, roxo, chinês e } \\
\text { japonês) "taro" }\end{array}$ & 5 & $\mathrm{hb}$ & al & il \\
\hline Spathiphyllum cannaefolium Schott & Copo-de-leite branco & 13 & $\mathrm{hb}$ & or & 154 \\
\hline S. wallisi Regel & Lírio-da-paz-miudo (branco) & 2 & hb & or & 376 \\
\hline Xanthosoma sagittifolium Schott & Taioba & 3 & hb & $\mathrm{al}$, or & il \\
\hline \multicolumn{6}{|l|}{ Araliaceae } \\
\hline Polyscias cf. balfouriana (hort. ex André) L.H. Bailey & Árvore-de-enfeite & 4 & at & or & il \\
\hline Schefflera actinophylla (Endl.) Harms & Chefléria & 2 & at & or & il \\
\hline \multicolumn{6}{|l|}{ Arecaceae } \\
\hline Bactris sp.1 & Pupunha-de-espinho, pupunha-espinhuda & 1 & $a b$ & al & il \\
\hline Cocos nucifera L. & Coco-da-baia & 18 & $a b$ & $\mathrm{al}, \mathrm{md}$ & 250 \\
\hline Dypsis lutescens (H. Wendl.) Beentje \& J. Dransf. & Coqueirinho & 19 & at & or & il \\
\hline Orbignya oleifera Burret & Babaçu, babaçu-do-mato & 1 & $a b$ & al & il \\
\hline Syagrus oleracea (Mart.) Becc. & Palmito-amargo, gueirova & 15 & $a b$ & al & il \\
\hline Syagrus sp.2 & Pupunha-lisa & 1 & $a b$ & al & il \\
\hline \multicolumn{6}{|l|}{ Araucariaceae } \\
\hline Araucaria sp.3 & Araucária & 1 & $a b$ & or & il \\
\hline \multicolumn{6}{|l|}{ Asteraceae } \\
\hline Ageratum conyzoides L. & Mentrasto, erva-de-são-joão & 7 & $\mathrm{hb}$ & md, al & 173 \\
\hline Artemisia absinthium L. & Losna, Iosninha & 7 & hb & $\mathrm{md}$ & $41.921^{\#}$ \\
\hline Baccharis trimera (Less.) DC. & Carqueja & 9 & hb & md & 379 \\
\hline Bidens pilosa L. & Picão, picão-preto & 6 & hb & md & il \\
\hline Coreopsis grandiflora Hogg ex Sweet & Camomila & 4 & $\mathrm{hb}$ & md & 186 \\
\hline C. lanceolata L. & Sem denominaçaõ local (ni) & 2 & $\mathrm{hb}$ & or & 138 \\
\hline Chrysanthemum leucanthemum L. & Margarida-branca & 4 & hb & or, md & 382 \\
\hline C. segetum $\mathrm{L}$. & Bom-senhor-amarelo & 8 & $\mathrm{hb}$ & or & 147 \\
\hline Cichorium endivia L. & $\begin{array}{l}\text { Almeirão, ameirão-amargo, almeirão-japonês, } \\
\text { almeirão-branco. }\end{array}$ & 11 & hb & al & il \\
\hline Emilia sonchifolia (L.) DC & Serralha, serralha-doce & 8 & $\mathrm{hb}$ & al & il \\
\hline Lactuca sativa L. & Alface & 4 & hb & $\mathrm{al}, \mathrm{md}$ & il \\
\hline Solidago chilensis L. & Arnica, arnica-do-campo, arniquinha & 13 & $\mathrm{hb}$ & or , md & 185 \\
\hline
\end{tabular}


Anexo 1 - Tabela 1 - Continuação.

\begin{tabular}{|c|c|c|c|c|c|}
\hline Nome Científico & Denominação Local & Nc & $\mathrm{Hb}$ & $\mathrm{Pi}$ & Ref. \\
\hline Tagetes erecta L. & Cravo-amarelo & 1 & hb & or & 152 \\
\hline Taraxacum officinale F.H. Wigg. & Dente-de-leão & 1 & hb & md & il \\
\hline Unxia kubitzkii H. Rob. & Enfeite & 7 & hb & or & 195 \\
\hline Vernonia condensata Baker & Caferana & 5 & hb & md & 191 \\
\hline Zinnia elegans Jacq. & $\begin{array}{l}\text { Capitão, bem-me-quer, capitão-vemelho, } \\
\text { capitão-amarelo. }\end{array}$ & 16 & hb & or , md & 117 \\
\hline Asterceae (indeterminada) & Boldo-japonês & 1 & at & md & il \\
\hline \multicolumn{6}{|l|}{ Balsaminaceae } \\
\hline Impatiens walleriana Hook. f. & $\begin{array}{l}\text { Beijo, beijo-roxo, beijo-japonês-branco, beijo- } \\
\text { cor-de-rosa, beijo-japonês-mesclado }\end{array}$ & 11 & hb & or & $\begin{array}{l}120,142 \\
143,144\end{array}$ \\
\hline \multicolumn{6}{|l|}{ Bignoniaceae } \\
\hline Crescentia cujete L. & Cabaça-de-árvore, coité & 2 & $a b$ & pni & il \\
\hline Tecoma stans (L.) Juss. ex Kunth & Sem denominação local (ni) & 2 & at & or & 170 \\
\hline \multicolumn{6}{|l|}{ Bixaceae } \\
\hline Bixa orellana L. & Urucum, coloral & 8 & $a b$ & al, md & 574 \\
\hline \multicolumn{6}{|l|}{ Boraginaceae } \\
\hline Cordia cf. ecalyculata Vell. & Chá-de-bugre, aporangaba. & 1 & $a b$ & md & il \\
\hline Symphytum officinale L. & Confrei & 6 & hb & md & il \\
\hline \multicolumn{6}{|l|}{ Brassicaceae } \\
\hline Brassica cf carinata A. Braun & Couve, couve-manteiga & 9 & hb & al & il \\
\hline B. rapa L. & Mostarda & 6 & hb & al & il \\
\hline Cleome hassleriana Chod. & Mussambê & 1 & $a b$ & md & 492 \\
\hline Eruca sativa Mill. & Rúcula & 8 & hb & al & il \\
\hline Nasturtium officinale R. Br. & Agrião & 3 & $\mathrm{hb}$ & al, md & il \\
\hline \multicolumn{6}{|l|}{ Bromeliaceae } \\
\hline Ananas comosus (L.) Merr. & Abacaxi-pérola, (pêra, branco e ananás) & 11 & $\mathrm{hb}$ & al & il \\
\hline \multicolumn{6}{|l|}{ Cactaceae } \\
\hline Cereus peruvianus (L.) J.S. Muell. & Mandacaru & 22 & at & md & il \\
\hline Opuntia vulgaris Mill. & Palma, figo. & 6 & at & or, al & il \\
\hline Nopalea cochenillifera (L.) Salm-Dyck & Palma-banana & 1 & at & md & il \\
\hline Rhipsalis baccifera (J.S. Muell.) Stearn & Cacto-pérola & 2 & ep & or & 495 \\
\hline Schlumbergera truncata (Haw.) Moran & Flor-de-maio-cor-de-rosa & 13 & $\mathrm{hb}$ & or & 153 \\
\hline \multicolumn{6}{|l|}{ Caricaceae } \\
\hline Carica papaya L. & $\begin{array}{l}\text { Mamão-macho, mamão-papaia, mamão- } \\
\text { formoso, mamão-engana-moleque }\end{array}$ & 23 & $a b$ & al, md & 172 \\
\hline \multicolumn{6}{|l|}{ Caryophyllaceae } \\
\hline Dianthus chinensis L. & $\begin{array}{l}\text { Cravo (morfotipos: cravo-bordô, branco, } \\
\text { vermelho, rosa, amarelo e mesclado) }\end{array}$ & 16 & hb & or & 490 \\
\hline \multicolumn{6}{|l|}{ Celastraceae } \\
\hline Maytenus ilicifolia (Schrad.) Planch. & Espinheira-santa, casca-sagrada & 8 & at & md & 128 \\
\hline \multicolumn{6}{|l|}{ Chrysobalanaceae } \\
\hline Licania tomentosa (Benth.) Fritsch & Oiti & 2 & $a b$ & or & il \\
\hline \multicolumn{6}{|l|}{ Clusiaceae } \\
\hline Hypericum perforatum L. & Erva-de-são-joão & 1 & hb & md & il \\
\hline
\end{tabular}


Anexo 1 - Tabela 1 - Continuação.

\begin{tabular}{|c|c|c|c|c|c|}
\hline Nome Científico & Denominação Local & Nc & $\mathrm{Hb}$ & $\mathrm{Pi}$ & Ref. \\
\hline \multicolumn{6}{|l|}{ Commelinaceae } \\
\hline Tradescantia pallida (Rose)D.R.Hunt & Enfeite & 9 & $\mathrm{hb}$ & or & 139 \\
\hline \multicolumn{6}{|l|}{ Convolvulaceae } \\
\hline Evolvulus glomeratus Nees \& C. Mart. & Enfeite & 8 & $\mathrm{pr}$ & or & 375 \\
\hline Ipomoea batatas (L.) Lam. & Batata-doce (branca, amarela e roxa) & 7 & $\mathrm{pr}$ & al & 209 \\
\hline \multicolumn{6}{|l|}{ Costaceae } \\
\hline Costus spicatus (Jacq.) Sw. & $\begin{array}{l}\text { Caninha-do-brejo, cana-de-macaco, banana- } \\
\text { de-macaco }\end{array}$ & 7 & hb & md & 165 \\
\hline \multicolumn{6}{|l|}{ Cucurbitaceae } \\
\hline Cucurbita maxima Duchense & Moranga & 1 & $\mathrm{pr}$ & al & il \\
\hline C. pepo L. & Abóbora-menina, abóbora & 1 & $\operatorname{tr}$ & al & 168 \\
\hline Cucurbita sp.4 & Abóbora-gigante & 1 & tr & al & il \\
\hline C. moschata Duchesne & Abóbora-comum, abobrinha & 9 & $\mathrm{pr}$ & al & il \\
\hline Momordica charantia L. & Melão-caetano, melão-caetano-grande & 4 & $\mathrm{pr}$ & al, md & 23 \\
\hline Sechium edule (Jacq.) Sw. & Chuchu & 5 & $\operatorname{tr}$ & al & il \\
\hline Cucurbitaceae (indeterminada) & Chuchu-gigante, chuchu-de-quilo & 2 & $\operatorname{tr}$ & al & ni \\
\hline \multicolumn{6}{|l|}{ Cupressaceae } \\
\hline Chamaecyparis sp.5 & Pinheirinho-de-natal & 2 & $a b$ & or & il \\
\hline \multicolumn{6}{|l|}{ Davalliaceae } \\
\hline Nephrolepis cordifolia (L.) C. Presl & Samambaia-de-metro & 13 & $\mathrm{hb}$ & or & il \\
\hline \multicolumn{6}{|l|}{ Dioscoreaceae } \\
\hline Dioscorea cf. bulbifera L. & Cara-muela, inhame & 1 & tr & al & il \\
\hline \multicolumn{6}{|l|}{ Equisetaceae } \\
\hline Equisetum giganteum $\mathrm{L}$. & Cavalinha, cavalinha-do-brejo & 2 & $\mathrm{hb}$ & md & 572 \\
\hline \multicolumn{6}{|l|}{ Ericaceae } \\
\hline Rhododendron sp.6 & Azaléia & 2 & at & or & 199 \\
\hline \multicolumn{6}{|l|}{ Euphorbiaceae } \\
\hline Euphorbia milii Des Moul. & Coroa-de-cristo, coroa-imperial & 5 & $\mathrm{hb}$ & or, md, tx & 578 \\
\hline E. pulcherrima Willd. ex Klotzsch & $\begin{array}{l}\text { Bico-de-papagaio, bico-de-papagaio- } \\
\text { vermelho, bico-de-papagaio-rosa }\end{array}$ & 10 & at & or, ra & 166 \\
\hline E. tirucalli $\mathrm{L}$. & Cancerosa-palitinho, & 5 & $\mathrm{hb}$ & md & il \\
\hline Jatropha curcas L. & Pinhão-branco & 1 & at & md & 234 \\
\hline J. gossypiifolia L. & Pinhão-roxo & 1 & at & md & 247 \\
\hline J. podagrica Hook. & Bálsamo & 5 & at & md, or & 581 \\
\hline Manihot esculenta Crantz & Mandioca (cacau, de 3meses e branquinha) & 16 & at & al & 277 \\
\hline Ricinus communis L. & Mamona & 3 & at & ol , md & il \\
\hline \multicolumn{6}{|l|}{ Fabaceae-Caesalpinioideae } \\
\hline Caesalpinia ferrea Mart. & Pau-ferro, árvore-pau-ferro & 1 & $a b$ & md & 742 \\
\hline C. pulcherrima (L.) Sw. & Brinco-de-princesa (vermelho) & 2 & at & or & 374 \\
\hline C. sepiaria Roxb. & Brinco-de-princesa (alaranjada) & 1 & at & or & 497 \\
\hline Hymenaea stigonocarpa Mart. ex Hayne & Jatobá, jatobá-do-cerrado & 1 & $a b$ & pni & 13 \\
\hline Senna occidentalis (L.) Link & Fedegoso & 3 & at & md & $42.001^{\#}$ \\
\hline Tamarindus indica L. & Tamarindo & 2 & $a b$ & al & 673 \\
\hline
\end{tabular}


Anexo 1 - Tabela 1 - Continuação.

\begin{tabular}{|c|c|c|c|c|c|}
\hline Nome Científico & Denominação Local & $\mathrm{Nc}$ & $\mathrm{Hb}$ & $\mathrm{Pi}$ & Ref. \\
\hline \multicolumn{6}{|l|}{ Fabaceae-Mimosoideae } \\
\hline Calliandra brevipes Benth. & Batata-de-bode, & 1 & at & pni & 150 \\
\hline Inga edulis Mart. & Ingá & 1 & $a b$ & al & 19 \\
\hline \multicolumn{6}{|l|}{ Fabaceae-Papilionoideae } \\
\hline Cajanus cajan (L.) Millsp & Feijão-andu, andu & 2 & sa & al & 401 \\
\hline Phaseolus vulgaris $\mathrm{L}$. & Feijão-comum & 2 & $\mathrm{hb}$ & al & il \\
\hline Vicia faba L. & Fava, feijão-fava & 2 & $\operatorname{tr}$ & al & il \\
\hline Vigna cf. unguiculata (L.) Walp. & Feijão-de-vara, feijão-de-corda & 3 & $\operatorname{tr}$ & al & il \\
\hline Vigna sp.7 & Feijão-orelha-de-padre, feijão-frade & 1 & $\operatorname{tr}$ & al & il \\
\hline Fabaceae-Papilionoideae (indeterminada) & Feijão-catadô, catadô & 2 & $\operatorname{tr}$ & al & $\mathrm{Ni}$ \\
\hline \multicolumn{6}{|l|}{ Heliconiaceae } \\
\hline Heliconia rostrata Ruiz \& Pav. & Bananeirinha & 2 & $\mathrm{hb}$ & or & 384 \\
\hline \multicolumn{6}{|l|}{ Hydrangeaceae } \\
\hline Hydrangea macrophylla (Thumb.) Ser. & Hortência & 17 & at & or & 146 \\
\hline \multicolumn{6}{|l|}{ Juncaceae } \\
\hline Juncus sp.8 & Junco & 3 & $\mathrm{hb}$ & $\mathrm{md}$ & il \\
\hline \multicolumn{6}{|l|}{ Lamiaceae } \\
\hline Hyptis suaveolens (L.) Poit. & Tapera-velha & 1 & $\mathrm{hb}$ & $\mathrm{md}$ & 532 \\
\hline Lavandula angustifolia Mill. & Levanda & 1 & $\mathrm{hb}$ & $\mathrm{md}, \mathrm{al}$ & il \\
\hline Leonotis nepetifolia (L.) R. Br. & Cordão-de-frade & 2 & $\mathrm{hb}$ & $\mathrm{md}$ & 381 \\
\hline Mentha piperita L. & Horlelã & 13 & $\mathrm{hb}$ & md & il \\
\hline M. pulegium L. & Poejo & 16 & $\mathrm{hb}$ & $\mathrm{md}$ & il \\
\hline Ocimum basilicum $\mathrm{L}$. & Manjericão & 3 & sa & $\mathrm{al}, \mathrm{md}$ & 499 \\
\hline 0. gratissimum L. & Alfavaca & 11 & $\mathrm{hb}$ & md & $41.984^{\#}$ \\
\hline Ocimum sp.9 & Sofre-do-rim-quem-quer & 3 & at & $\mathrm{md}$ & 496 \\
\hline Origanum vulgare $\mathrm{L}$. & Orégano, mangerona & 2 & $\mathrm{hb}$ & al & il \\
\hline Plectranthus barbatus Andrews & Boldo & 17 & $\mathrm{hb}$ & md & 171 \\
\hline Plectranthus sp.10 & Hortelanzão & 3 & $\mathrm{hb}$ & md & 484 \\
\hline Salvia officinalis $\mathrm{L}$. & Salvia & 1 & $\mathrm{hb}$ & al & il \\
\hline Solenostemon scutellarioides (L.) Codd. & Folhagem-vermelha, folhagem-amarela & 8 & $\mathrm{hb}$ & or & 125 \\
\hline Rosmarinus officinalis L. & Alecrim & 14 & $\mathrm{hb}$ & $\mathrm{md}$ & il \\
\hline \multicolumn{6}{|l|}{ Lauraceae } \\
\hline Cinnamomum zeylanicum Blume & Canela, canela-de-casca & 5 & $a b$ & $\mathrm{al}, \mathrm{md}$ & il \\
\hline Laurus nobilis L. & Louro & 2 & at & al & il \\
\hline \multicolumn{6}{|l|}{ Liliaceae* $^{*}$} \\
\hline Allium fistulosum $\mathrm{L}$. & Cebolinha-de-folha, cebolinha-de-conserva. & 26 & $\mathrm{hb}$ & al & il \\
\hline A. sativum $\mathrm{L}$. & Alho (comum, japonês e aipoidirruon) & 9 & $\mathrm{hb}$ & al & il \\
\hline Aloe vera (L.) Burm. f. & Babosa, silué & 20 & $\mathrm{hb}$ & $\mathrm{md}$ & il \\
\hline Chlorophytum comosum (Thunb.) Jacques & Folhaginha & 14 & $\mathrm{hb}$ & or & 192 \\
\hline Cordyline terminalis (L.) Kunth & Folhagem & 4 & at & or & 167 \\
\hline Herreria salsaparilha Mart. & Salsaparrilha, salsa-paredão & 6 & $\operatorname{tr}$ & $\mathrm{md}$ & il \\
\hline Sansevieria trifasciata Prain & Espada-de-são-jorge & 6 & $\mathrm{hb}$ & or, mt & 385 \\
\hline
\end{tabular}


Anexo 1 - Tabela 1 - Continuação.

\begin{tabular}{|c|c|c|c|c|c|}
\hline Nome Científico & Denominação Local & Nc & $\mathrm{Hb}$ & $\mathrm{Pi}$ & Ref. \\
\hline Cuphea carthagenensis (Jacq.) J.F. Macbr. & Sete-sangria & 1 & $\mathrm{hb}$ & $\mathrm{md}$ & il \\
\hline Lagerstroemia indica L. & $\begin{array}{l}\text { Arvinha-de-natal-branca, arvinha-de-natal- } \\
\text { roxa. }\end{array}$ & 9 & $a b$ & or & 582 \\
\hline Punica granatum $\mathrm{L}$. & Romã, mini-romã, romã-de-jardim & 14 & $a b$ & $\begin{array}{l}\mathrm{al}, \mathrm{md} \text {, } \\
\text { or }\end{array}$ & 181 \\
\hline \multicolumn{6}{|l|}{ Malpighiaceae } \\
\hline Malpighia glabra L. & Acerola & 20 & $a b$ & al & $41.908^{\#}$ \\
\hline \multicolumn{6}{|l|}{ Malvaceae } \\
\hline Dombeya wallichii (Lindl.) K. Schum. & Árvore-estrapeia & 1 & $a b$ & pni & il \\
\hline Gossypium hirsutum L. & Algodão, algodão-anul & 3 & $\mathrm{hb}$ & md & il \\
\hline Gossypium sp.11 & Algodão-de-árvore & 1 & $a b$ & md & $42.028^{\#}$ \\
\hline Abelmoschus esculentus (L.) Moench & Quiabo, quiabo-comum & 7 & sa & al & il \\
\hline Hibiscus rosa-sinensis $\mathrm{L}$. & $\begin{array}{l}\text { Hibiscus-vermelho, hibisco-grande-dobrado, } \\
\text { hibiscus-rosa }\end{array}$ & 3 & at & or & 148 \\
\hline Hibiscus sp.12 & Beijão, chorãozinho & 3 & at & or & 169 \\
\hline Theobroma grandiflorum (Willd. ex. Spreng.) K. Schum. & Cupuaçu & 4 & $a b$ & al & il \\
\hline \multicolumn{6}{|l|}{ Marantaceae } \\
\hline Maranta arundinacea L. & Araruta & 1 & $\mathrm{hb}$ & md & il \\
\hline \multicolumn{6}{|l|}{ Melastomataceae } \\
\hline Schizocentron elegans (Schltdl.) Meisn & Flor-do-Taba-hotel & 1 & $\mathrm{hb}$ & or & 115 \\
\hline \multicolumn{6}{|l|}{ Moraceae } \\
\hline Artocarpus altilis (Parkinson) Fosberg & Fruta-pão & 1 & $a b$ & $\mathrm{al}, \mathrm{md}$ & il \\
\hline A. integrifolia L. f. & Jaca & 2 & $a b$ & al & il \\
\hline Ficus carica L. & Figo & 5 & at & $\mathrm{al}, \mathrm{md}$ & il \\
\hline \multicolumn{6}{|l|}{ Musaceae } \\
\hline Musa paradisiaca L.(cultivar AAA - cavendish) & $\begin{array}{c}\text { Banana-nnica, banana-nanicão, banana- } \\
\text { d'água }\end{array}$ & 13 & at & al & il \\
\hline M. paradisiaca L. (cultivar AAB - subgrupo "plantain") & $\begin{array}{l}\text { Banana-de-fritar, banana-maranhão, banana- } \\
\text { da terra. }\end{array}$ & 9 & at & al & il \\
\hline M. paradisiaca L. (cultivar AAB maçã) & Banana-maçã & 2 & at & al & il \\
\hline M. paradisiaca L. (cultivar AAB) & Banana-são-tomé & 2 & at & al & il \\
\hline \multicolumn{6}{|l|}{ Myrtaceae } \\
\hline Eugenia pitanga (0. Berg) Kiaersk. & Pitanga & 13 & $a b$ & al & 179 \\
\hline E. stipitata Mc Vaugh & Araçá & 6 & $a b$ & al & 180 \\
\hline Myrciaria cauliflora (Mart.) 0. Berg. & Jaboticaba & 18 & $a b$ & $\mathrm{al}$ & il \\
\hline Psidium guajava L. & Goiaba & 16 & $a b$ & $\mathrm{al}, \mathrm{md}$ & il \\
\hline Syzygium jambos (L.) Alston & Jambo, jambo-baiano & 1 & $a b$ & al & il \\
\hline S. malaccense (L.) Merr. \& L.M.Perry & Jambo-vermelho & 1 & $a b$ & or, al & il \\
\hline \multicolumn{6}{|l|}{ Nyctaginaceae } \\
\hline Bougainvillea spectabilis Willd. & Primavera-rosa-dobrada & 1 & $\operatorname{tr}$ & or & 183 \\
\hline B. glabra Choisy & Primavera-lilás-forte & 4 & $\operatorname{tr}$ & or & 189 \\
\hline \multicolumn{6}{|l|}{ Oleaceae } \\
\hline Jasminum pubescens (Retz.) Willd. & Jasmim & 2 & at & or & 145 \\
\hline \multicolumn{6}{|l|}{ Orchidaceae } \\
\hline Cattleya nobilior Rchb. f. & Orquídea, orquídea-roxa & 9 & ep & or & il \\
\hline
\end{tabular}


Anexo 1 - Tabela 1 - Continuação.

\begin{tabular}{|c|c|c|c|c|c|}
\hline Nome Científico & Denominação Local & Nc & $\mathrm{Hb}$ & $\mathrm{Pi}$ & Ref. \\
\hline Cattleya sp.13 & $\begin{array}{l}\text { Orquídeas (com flores de diferentes cores e } \\
\text { dimensões). }\end{array}$ & 12 & ep & or & il \\
\hline Cymbidium sp.14 & $\begin{array}{c}\text { Orquídea (de flores amarelas, rosas e } \\
\text { brancas) }\end{array}$ & 7 & ep & or & il \\
\hline Cyrtopodium palmifrons Rchb. f. \& Warm. & $\begin{array}{l}\text { Orquídea-de-cacho-amarelo, Orchidea-de- } \\
\text { coqueiro }\end{array}$ & 2 & ep & or & 42 \\
\hline Orchidaceae (indeterminada) & Orquídea & 1 & ep & or & 174 \\
\hline \multicolumn{6}{|l|}{ Oxalidaceae } \\
\hline Averrhoa carambola L. & Carambola & 6 & $a b$ & $\mathrm{al}, \mathrm{md}$ & 388 \\
\hline Oxalis triangularis A. St -Hil. & Trevo-roxo & 12 & hb & or & 194 \\
\hline \multicolumn{6}{|l|}{ Passifloraceae } \\
\hline Passiflora edulis Sims & Maracujá & 12 & $\operatorname{tr}$ & al, md & 124 \\
\hline Passiflora sp.15 & Maracujina-vermelha & 1 & $\operatorname{tr}$ & al, md & 93 \\
\hline \multicolumn{6}{|l|}{ Phyllanthaceae } \\
\hline Phyllanthus tenellus Roxb. & Quebra-pedra & 18 & hb & md & il \\
\hline \multicolumn{6}{|l|}{ Phytolaccaceae } \\
\hline Petiveria alliacea L. & Guiné, guiné-da-índia, gambá. & 18 & $\mathrm{hb}$ & $\mathrm{md}, \mathrm{mt}$ & 486 \\
\hline \multicolumn{6}{|l|}{ Piperaceae } \\
\hline Piper nigrum L. & Pimenta-do-reino & 8 & $\operatorname{tr}$ & al & il \\
\hline P. umbellatum L. & Jaborandi & 1 & at & md & 380 \\
\hline \multicolumn{6}{|l|}{ Plantaginaceae } \\
\hline Plantago major L. & Tanchagem & 12 & $\mathrm{hb}$ & md & 200 \\
\hline Russelia equisetiformis Schltdl. \& Cham. & Rabo-de-pavão, brinco-de-princesa & 7 & $\mathrm{hb}$ & or, md & 370 \\
\hline \multicolumn{6}{|l|}{ Plumbaginaceae } \\
\hline Plumbago capensis Thunb. & Sem denominação local (ni) & 1 & $\operatorname{tr}$ & or & 493 \\
\hline \multicolumn{6}{|l|}{ Poaceae } \\
\hline Coix lacryma-jobi L. & $\begin{array}{l}\text { Conta-de-lágrima, são-josé, } \\
\text { conta-milagrosa }\end{array}$ & 3 & $\mathrm{hb}$ & or, md, at & 155 \\
\hline Zea mays L. & Milho & 3 & hb & al & il \\
\hline Cymbopogon citratus (DC.) Stapf & Capim-santo, capim-cidreira & 9 & hb & md & 281 \\
\hline C. flexuosus (Nees ex Steud.) Will.Watson & Capim-eucalipto, capim-acaipe & 1 & hb & md & il \\
\hline \multicolumn{6}{|l|}{ Polygonaceae } \\
\hline Antigonon guatimalense Meisn. & Amor-juntinho & 4 & $\operatorname{tr}$ & or & 140 \\
\hline Polygonum ferrugineum Wedd. & Erva-de-bicho (da beira do rio) & 1 & hb & md & 90 \\
\hline \multicolumn{6}{|l|}{ Polypodiaceae } \\
\hline Polypodium decumanum Willd. & Samambaia & 14 & ep & or & 397 \\
\hline \multicolumn{6}{|l|}{ Portulacaceae } \\
\hline Portulaca oleracea L. & $\begin{array}{l}\text { Onze-horas-alaranjada, onze-horas-amarela, } \\
\text { ora-por-nobe, fura-tacho }\end{array}$ & 7 & hb & or, aa & 119 \\
\hline \multicolumn{6}{|l|}{ Pteridaceae } \\
\hline Adiantum raddianum $\mathrm{C}$. Presl. & Avenca & 13 & hb & or & il \\
\hline Pityrogramma calomelanos (L.) Link var. calomelanos & Samambaia-do-brejo & 6 & hb & or & 1.051 \\
\hline \multicolumn{6}{|l|}{ Rosaceae } \\
\hline Eriobotrya japonica (Thunb.) Lindl. & Nêspera & 1 & $a b$ & al & il \\
\hline Fragaria sp.16 & Morango, moranguinho & 2 & $\mathrm{hb}$ & al & il \\
\hline
\end{tabular}


Anexo 1 - Tabela 1 - Continuação.

\begin{tabular}{|c|c|c|c|c|c|}
\hline Nome Científico & Denominação Local & Nc & $\mathrm{Hb}$ & $\mathrm{Pi}$ & Ref. \\
\hline Prunus domestica L. & Ameixa & 1 & $a b$ & al & il \\
\hline Prunus sp.17 & Cereja & 1 & at & al & il \\
\hline Rosa chinensis Jacq. & Rosa-menina, roseira-menina-vermelha & 9 & hb & or & 158 \\
\hline Rosa $\times$ grandiflora Lindl. & Roseira-príncipe-encantado, & 18 & sa & or & 161 \\
\hline Rosa sp. 18 & Rosa-salmão & 2 & sa & or & 159 \\
\hline Rosa sp. 19 & Roseira-cafelista & 2 & sa & or & 488 \\
\hline Rosa sp. 20 & Roseira-santista & 1 & hb & or & il \\
\hline Rosa sp. 21 & Rosa-vermelho-vivo & 1 & sa & or & 160 \\
\hline Rosa sp. 22 & Roseira-principe-negro & 1 & sa & or & il \\
\hline Rosa sp. 23 & Roseira de cacho-cor-de-rosa & 10 & $\operatorname{tr}$ & or & 157 \\
\hline \multicolumn{6}{|l|}{ Rubiaceae } \\
\hline Coffea arabica L. & Café (cultivares vermelho, amarelo e gigante) & 6 & $a b$ & al & il \\
\hline Ixora finlaysoniana Wall. ex G. Don & Ixorio-gigante, ixoria-branca & 1 & at & or & 487 \\
\hline I. macrothyrsa Teijsm. \& Binn. & Ixoria-vermelha & 1 & at & or & 483 \\
\hline I. coccinea L. & Ixora-pequena & 15 & at & or & 126 \\
\hline I. undulata Roxb. & Ixora-cor-de-rosa & 3 & at & or & 573 \\
\hline Mussaenda erythrophylla Schumach. \& Thonn. & Mussaenda & 4 & at & or & 133 \\
\hline M. philippica A. Rich. & Mussaenda-palha & 3 & at & or & 130 \\
\hline \multicolumn{6}{|l|}{ Rutaceae } \\
\hline Citrus aurantifolia (Christm.) Swingle & Limão-taiti & 4 & $a b$ & $\mathrm{al}, \mathrm{md}$ & il \\
\hline C. cf. aurantifolia (Christm.) Swingle & Limão-galego & 7 & $a b$ & $\mathrm{al}, \mathrm{md}$ & il \\
\hline C. limonia (L.) Osbeck & Limão-cravo, limão-rosa, limão-comum & 9 & $a b$ & $\mathrm{al}, \mathrm{md}$ & il \\
\hline C. limettioides Tanaka & Lima & 3 & $a b$ & $\mathrm{md}$ & il \\
\hline C. medica L. & Laranja-cidra, Iaranja-de-doce & 2 & $a b$ & al & il \\
\hline C. reticulata Blanco & Tagerinas (mexirica, moricota, poncã) & 10 & $a b$ & al & il \\
\hline C. sinensis (L.) Osbeck & $\begin{array}{l}\text { Laranja, Iaranja-comum, laranja-pêra, Iaranja- } \\
\text { de-doce, laranja-baiana. }\end{array}$ & 6 & $a b$ & al & 52 \\
\hline Ruta graveolens $\mathrm{L}$. & Arruda & 17 & $\mathrm{hb}$ & $\begin{array}{l}\text { md, as, } \\
\text { or, mt }\end{array}$ & 176 \\
\hline \multicolumn{6}{|l|}{ Salicaceae } \\
\hline Casearia sylvestris Sw. & Espeteiro, espeteiro-do-mato & 1 & $a b$ & pni & il \\
\hline \multicolumn{6}{|l|}{ Sapotaceae } \\
\hline Pouteria glomerata (Miq.) Radlk. & Laranjinha & 1 & $a b$ & pni & $42.058^{\#}$ \\
\hline \multicolumn{6}{|l|}{ Solanaceae } \\
\hline $\begin{array}{l}\text { Brugmansia suaveolens (Humb. \& Bonpl. ex Willd.) Bercht. \& J. } \\
\text { Presl }\end{array}$ & Beladona-branca & 3 & at & md, or & 175 \\
\hline Capsicum annuum L. & Pimentão & 2 & hb & al & il \\
\hline C. baccatum $\mathrm{L}$. & $\begin{array}{l}\text { Pimenta-cumari, pimenta-cumbari, pimenta- } \\
\text { pombari, pombari. }\end{array}$ & 7 & $\mathrm{hb}$ & al & il \\
\hline C. chinense Jacq. & Pimenta-bode, pimenta-de-cheiro, & 17 & $\mathrm{hb}$ & al & il \\
\hline C. frutescens $\mathrm{L}$. & Pimenta-malagueta, malagueta-doce & 11 & $\mathrm{hb}$ & al & il \\
\hline Capsicum sp.24 & Pimenta-bodona & 1 & $\mathrm{hb}$ & al & 1.353 \\
\hline Capsicum sp.25 & Pimenta-de-enfeite, mini-pimenta & 6 & hb & or & 1.354 \\
\hline
\end{tabular}


Anexo 1 - Tabela 1 - Continuação.

\begin{tabular}{|c|c|c|c|c|c|}
\hline Nome Científico & Denominação Local & Nc & $\mathrm{Hb}$ & $\mathrm{Pi}$ & Ref. \\
\hline Capsicum sp.26 & Pimenta-bodinho, Pimenta-bode-preta & 2 & hb & al & 1.355 \\
\hline Capsicum sp.27 & Pimenta-bugre & 1 & $\mathrm{hb}$ & al & 1.356 \\
\hline Capsicum sp.28 & Pimenta doce, pimenta-de-fritar & 8 & hb & al & 1.384 \\
\hline Capsicum sp.29 & Pimenta-doce ou chifre de veado & 1 & hb & al & 1.385 \\
\hline Capsicum sp.30 & Pimenta-dente-de-leão & 1 & $\mathrm{hb}$ & al & 1.386 \\
\hline Capsicum sp.31 & Pimenta-coração-de-galinha & 1 & $\mathrm{hb}$ & al & 1.387 \\
\hline Capsicum sp.32 & Pimenta-chapéu-de-bispo & 1 & hb & al & 1.388 \\
\hline Capsicum sp.33 & Pimenta-dedo-de-moça & 4 & $\mathrm{hb}$ & al & 1.392 \\
\hline Lycopersicum esculentum Mill. & Tomate, tomate comum & 8 & hb & al & il \\
\hline L. pimpinellifolium Dunal & $\begin{array}{l}\text { Tomatinho, tomatinho-azedo, tomatinho-pera, } \\
\text { tomatinho-caipira }\end{array}$ & 11 & hb & al & il \\
\hline Nicotiana tabacum L. & Fumo & 9 & hb & is & 491 \\
\hline Petunia axillaris (Lam.) Britton, Stern \& Poggenb. & Biscatinha & 5 & $\mathrm{hb}$ & or & 121 \\
\hline Solanum americanum Mill. & Maria-preta & 2 & hb & $\mathrm{md}, \mathrm{al}$ & il \\
\hline S. gilo Raddi & Jiló, gilozão & 2 & hb & al & il \\
\hline S. paniculatum L. & Jurubeba & 7 & at & md & 177 \\
\hline S. scabrum Mill. & Beringela & 1 & hb & al & il \\
\hline \multicolumn{6}{|l|}{ Turneraceae } \\
\hline Turnera ulmifolia L. & Guaxuma-de-jardim & 1 & $\mathrm{hb}$ & or & 579 \\
\hline \multicolumn{6}{|l|}{ Urticaceae } \\
\hline Cecropia pachystachya Trécul & Embaúba & 2 & $a b$ & pni & 301 \\
\hline Pilea microphylla (L.) Liebm. & Brilhantina média & 7 & hb & or & 386 \\
\hline P. nummulariifolia (Sw.) Wedd. & Folhaginha, dinheiro-em-penca & 6 & $\mathrm{hb}$ & or & 188 \\
\hline \multicolumn{6}{|l|}{ Verbenaceae } \\
\hline Clerodendron thomasonae Balf. & Cipó-trepadeira, lágrima-de-cristo & 3 & $\operatorname{tr}$ & or & 151 \\
\hline Duranta repens L. & Pingo-de-ouro & 14 & $a b$ & or & 197 \\
\hline Lantana camara Linn & Cambará, cambarazinho & 1 & at & or & 118 \\
\hline Lippia alba (Mill.) N.E. Br. & Erva-cidreira-de-folha, & 12 & sa & $\mathrm{md}, \mathrm{al}$ & 164 \\
\hline Petrea subserrata Cham. & Árvore-de-natal & 1 & $a b$ & or & 576 \\
\hline Priva bahiensis A. DC. & Sem denominação local (ni) & 1 & hb & pni & 577 \\
\hline Stachytarpheta cayennensis (Rich.) Vahl & Gervão & 4 & $\mathrm{hb}$ & md & 123 \\
\hline Tectona grandis L. f. & Teca & 1 & $a b$ & or & il \\
\hline Verbena ×hybrida Groenl. \& Rumpler & Colchão-de-niva-vermelho & 1 & $\mathrm{hb}$ & or & 116 \\
\hline \multicolumn{6}{|l|}{ Vitaceae } \\
\hline Cissus cf. verticillata (L.) Nicolson \& C.E. Jarvis & Insulina, insulina-de-cipó & 1 & $\operatorname{tr}$ & md & il \\
\hline Vitis sp.34 & Uva (rosada e Izabel) & 1 & $\operatorname{tr}$ & al & il \\
\hline \multicolumn{6}{|l|}{ Zingiberaceae } \\
\hline Alpinia zerumbet (Pers.) B.L. Burtt \& R.M. Sm. & Nóz-moscada & 5 & $\mathrm{hb}$ & md & 371 \\
\hline A. purpurata (Vieill.) K. Schum. & Bananeirinha & 2 & $\mathrm{hb}$ & or & 127 \\
\hline Curcuma longa L. & Açafrão & 15 & hb & al & il \\
\hline Zingiber officinale Roscoe & Gengibre & 17 & hb & $\mathrm{md}, \mathrm{al}$ & il \\
\hline Coletada e não identificada & Bloquel-de-noiva & 1 & at & or & 575 \\
\hline
\end{tabular}

